\title{
Swarms: Spatiotemporal Grouping Across Domains
}

\begin{abstract}
This paper presents cross-domain evidence that natural language makes use of (at least) two ways of individuating collective entities that differ in terms of how they cohere. The first kind, which I call swarm reference, picks out higher-order collective entities defined in terms of the spatial and temporal configuration of their constituent individuals. The second, which corresponds to canonical cases of group reference (e.g. committee, team, etc.), makes use of non-spatiotemporal notions. To motivate this distinction, I present systematic differences in how these two types of collective reference behave linguistically, both in the individual and event domains. These differences support two primary results. First, they are used as tests to isolate a new class of collective nouns that denote swarm individuals, both in English, as well as other languages like Romanian. I then consider a crosslinguistically common type of pluractionality, called event-internal in the previous literature (Cusic 1981; Wood 2007), and show that its properties are best explained if the relevant verbs denote swarm events. By reducing event-internal pluractionality to a type of collective reference also available for nouns, this work generates a new strong argument that pluractionality involves the same varieties of plural reference in the event domain that are seen in the individual domain.
\end{abstract}

Keywords: groups, pluractionality, plurality, cross-domain parallels

\section{Introduction}

Two assumptions run through much modern work on the formal semantics of verbs: (i) verbs are predicates of events, just like nouns are predicates of individuals, and (ii) the domain of events has a similar lattice structure as the domain of individuals (Krifka 1989, 1992; Landman 2000; Lasersohn 1995; Link 1998; Rothstein 2004, among many others). ${ }^{1}$ The formal similarity means that, in principle, the same kinds of denotations should be available for both nouns and verbs, as well as nominal and verbal modifiers. There is support for this position, for instance, in the long strand of classic work on telicity and its formal similarity to the count/mass distinction (e.g., Bach 1981, 1986; Krifka 1989, 1992; Mourelatos 1978; Taylor 1977). What is still an open question, though, is how far these parallels go. Is it the case that there is a one-to-one mapping in natural language between varieties of nominal reference to individuals and varieties of verbal reference to events with similar semantic properties? While comprehensively addressing this question is clearly beyond the scope of this work, my more modest goal in this article is to show

\footnotetext{
${ }^{1}$ We cannot say the same lattice structure because there is some disagreement in the literature about the existence of atomic events and whether the event lattice should be complemented, that is, whether for every individual there exists something that corresponds to everything that is not that individual.
} 
that taking a cross-categorial perspective on plural reference lets us draw new connections between a variety of under-studied constructions across unrelated languages. In particular, this paper identifies a novel way that higher-order individuation is done in natural language over collections of individuals and of events, which I call swarm reference. I show that a subset of collective nouns in English have swarm reference, and in virtue of this, have different semantic properties than canonical collective nouns like committee, which denote higher-order entities that are individuated in a different way. I then show that the properties of a typologically common class of pluractional verbs, called eventinternal in the previous literature (Cusic 1981; Wood 2007), can be best accounted for if these verbs have swarm reference in the event domain. Finally, I argue that not only do languages make use of this same variety of higher-order individual across both the event and individual domains, but that we find compositional similarities as well. In particular, there are swarm nouns in languages like Romanian which stand in the same derivational relationship to an underlying noun stem as pluractionals do to an underlying verb stem. The result is novel evidence for rich noun/verb denotational and compositional parallels, as well as insights into the semantics of pluractionality, which has been much less well studied than nominal plurality.

Before digging into the data, let's first consider in brief the phenomena that motivate the analysis. The nominals in (1) are classically known as collective nouns (Jespersen 1924/1992), but have come to be called group nouns (Barker 1992; Landman 1989a,b; Link 1983/2002). What sets them apart from standard count nouns is that, while they are morphologically singular, they behave in many ways as if they were plural.

\section{(1) GROUP NOUNS}
a. committee
b. team
c. family
d. group

The central question that group nouns raise is how an expression can lead a double life, manifesting properties of both singular and plural reference. One of the primary empirical results of this work is that there is more than one way to do so. The evidence comes from a second class of nominals, illustrated in (2), which I call swarm nouns. Like group nouns, swarm nouns share properties with both singular and plural count nouns. (For this reason, when I need to refer to both group and swarm nouns together, I will use Jespersen's term, collective noun, as a supercategory). ${ }^{2}$ More importantly, I show that swarm nouns behave differently than canonical group nouns on a subset of the standard diagnostics, which motivates an analysis in which they have different varieties of collective reference.

\footnotetext{
${ }^{2}$ This is an acknowledged abuse of terminology because collective noun and group noun are usually used synonymously. It is the best option, though. I do not want to rename the class of canonical group nouns, nor provide a new name for a category containing them. The term collective noun is less used, which is why I chose it for re-appropriation.
} 


\section{(2) SWARM NOUNS}
a. grove
b. bouquet
c. horde
d. swarm

It is important to note that while I will continue to compare the nouns in (2) and those in (1), I do not take these two classes of nouns to exhaust the subcategories of collective nouns. There is good reason to believe that the space of collective nouns is richly structured, and some ways of categorizing collective nouns could crosscut the distinction I make between group and swarm nouns. For instance, Persson 1989 argues for categories based on features like volition and mobility, Pearson 2011 uses intensionality as core feature of a subclass of collective nouns, and Ritchie 2013, in principle, allows for as many classes as there are ways to categorize the space of directed labeled graphs. ${ }^{3}$ The comparison between (1) and (2) is still informative, though, for two reasons. First, much of the previous work in the formal semantics of collective nouns has focused on collective nouns like those in (1), making them a good place from which to start a comparison. Second, whatever other ways we might classify collective nouns, I will show that group nouns and swarm nouns differ in that the individuals they denote are related to their constituent pluralities in different ways, and that variation in their semantic properties follows from this difference.

At an intuitive level, the core difference between groups and swarms - the kinds of individuals that fall in the extensions of (1) and (2), respectively-concerns the relationship that allows a plurality to cohere as a single individual. A grove is a grove because its constituent trees stand in a particular spatial configuration at a particular time. If the trees are moved, the grove ceases to exist. This is not just the case for a committee and its members; the noun committee places no conditions on the spatial or temporal relationships that hold between the members of committees in its extension. The idea I develop from this observation is that natural language makes use of two ways of individuating higher-order collective entities. On one hand, nouns like committee will denote individuals that are collective in virtue of being related to a plurality via the notion of membership. In contrast, nouns like grove will denote collective individuals in virtue of spatiotemporally coinciding with a plurality. The idea that nouns can denote individuals that are individuated in terms of their spatiotemporal properties is not new (see, for example, Gupta 1980 and Krifka 1990 on phase nouns like passenger which denote stages of individuals in transit), this is novel claim for individuating higher-order collective entities. The goal for the first part of the paper, then, is to formally define the notions of membership and spatiotemporal

\footnotetext{
${ }^{3}$ It is important to highlight Pearson 2011, which draws a distinction between committee-type group nouns and "collection nouns", which might at first pass seem similar to swarm nouns. These are group nouns that require an of-complement headed by an inanimate NP, for example, bunch of flowers, pile of dishes, deck of cards. While these group nouns share similar properties with swarms nouns, they are also different. In particular, swarm nouns do not need an of-complement, are not always inanimate, do not trigger plural agreement in British English, and are more opaque to distributors like one by one. Since they do not pass these tests, they can be separated from both group nouns and Pearson's collection nouns. Digging into this contrast, though, will have to wait for future work.
} 
superposition that allow for these two types of collective individuals to be defined, and to show that nouns that denote these kinds of individuals are expected to behave differently.

The second major result of this work follows from the account of swarm reference and links back to the larger questions I raised above concerning noun/verb denotational parallels. Many languages, especially those of Africa and the Americas, have morphologically derived pluractional verbs (see Cusic 1981; Wood 2007 for typological overviews). While various phenomena have been discussed under the heading of pluractionality, I use this term to refer to morphology that derives verbs that cannot be satisfied in single-event scenarios. If we assume that verbs are simple predicates of events, then at first glance, pluractional morphology looks similar to plural derivation in the nominal domain. It would derive verbal predicates with plural reference in the domain of events. What I will argue is that a crosslinguistically common type of pluractional, first called event-internal by Cusic (1981), derives verbal predicates with the same kind of plural reference as swarm nouns.

The following attested near-minimal pairs from the Mayan language Kaqchikel illustrate the phenomenon. ${ }^{4}$ The verb chuq' means to wound or pierce with a sharp object. It can be used in a simple transitive clause like (3a) to describe a graceful slaughter in which the knife pierces the cow's neck only once. Crucially, example (3b), which bears the event-internal pluractional $-\mathrm{Ca}$, cannot faithfully describe a scenario like this. Instead, it requires multiple piercings in rapid succession. Speakers, asked to describe appropriate scenarios for (3b), imagine a butcher furiously hacking at the cow's neck, trying to remove its head, but making slow progress. While there are a variety of tests to determine whether a pluractional verb is event-internal (see §3), the core idea is that such verbs describe repetitions that take place within what is conceived of as a single event.

(3) Event-internal Pluractional -CA' (Chacach, Cali \& Cojtí 1999: p. 58)

a. Ri ajch'olöy wakx, $n$-Ø-u-chuq'-ij ru-qül ri wakx r-ichin The butcher cow ICP-A3s-E3s-pierce-SS E3s-neck the cow E3s-reason $n i-\emptyset-k \ddot{a m}$. ICP-A3s-die

'The cow-butcher pierces the cow's neck to kill it.'

b. Ri ajch'olonel n-Ø-u-chuq'-cha' ru-qül ri mama' wakx. the butcher ICP-A3s-E3s-pierce-Ca' E3s-neck the big cow

'The butcher keeps stabbing at the big cow's neck.'

\footnotetext{
${ }^{4}$ Kaqchikel is one of about thirty extant Mayan languages spoken throughout Mesoamerica. Kaqchikel is a K'ichean language belonging to the Eastern Branch of the Mayan language family. In particular, Kaqchikel is spoken in the western highlands of Guatemala, north and west of Lago Atitlán, by over 500,000 people (Richards 2003).

${ }^{4}$ Glossing Conventions: 1=First Person, 2=Second Person, 3=Third Person, A=Absolutive, $\mathrm{ART}=$ Article, $\mathrm{CAUS}=$ Causative, $\mathrm{CLF}=\mathrm{Classifier}, \mathrm{CP}=$ Completive Aspect, $\mathrm{DIM}=$ diminutive, DAT=Dative, DIR=Directional, E=Ergative, ICP=Incompletive, IMP=imperative, IRR=Irrealis, ITR=Iterative, $\mathrm{NEG}=$ negation, $\mathrm{NOM}=$ nominalizer, $\mathrm{PAS}=$ Passive, $\mathrm{p}=$ Plural Person, $\mathrm{PL}=$ Plural, $\mathrm{RED}=$ Reduplicant, REFL=Reflexive, REP=Repetitive, $S S=$ Status Suffix, VTD=Derived Transitive Verb
} 
There is still a lot of work to do to determine the truth conditions of the pluractional in (3b), work that I will do subsequently, but it should be clear from this rough comparison that the pluractional requires a plurality of events that would satisfy the underlying predicate. Moreover, this plurality must be of relatively large cardinality, and each member must take place within a circumscribed spatial and temporal location. After arguing that these properties are among the core features of event-internal pluractionals crosslinguistically, I will show that they are accounted for if chuq'ucha' in (3b), as well as event-internal pluractional verbs more generally, have swarm reference in the event domain. This establishes that this way of individuating collective entities is active in both the nominal and verbal domains.

The analysis has the following structure. First, $§ 2$ motivates swarms as a distinct type of collective reference by showing that swarm nouns behave differently than canonical group nouns on a variety of tests. This section also provides a formal account of swarm reference based on the idea that swarm nouns denote atomic individuals whose spatial trace is saturated with the entities that compose the swarm. $\S 3$ then turns to event-internal pluractionality. I first show that the Kaqchikel verb stems derived by $-\mathrm{Ca}$ ' above in (3) patterns like a canonical event-internal pluractional. The second half of this section shows then that these properties can be accounted for if event-internal pluractionals have swarm reference in the event domain. The final substantive section, namely $\S 4$, considers cases in other languages where swarm nouns are derived by special morphology, parallel to how event-internal pluractionals are swarm verbs derived by special morphology. $§ 5$ concludes.

\section{Groups vs Swarms in the Nominal Domain}

Recall that collective nouns are a subset of count nouns. That is, they participate in the singular / plural contrast. Swarm nouns pattern with group nouns in this way. We have committee/committees and team/teams, as well as grove/groves and bouquet/bouquets. This observation leads us to our first test, from Barker 1992, who defines group nouns as those that can take a bare plural of-complement, but not a singular one. The intuition behind the test is that of-complements specify what constitutes the head noun. With group nouns, like (4), the head noun denotes individuals that must be constituted by a plurality, not mass or kind entities. This is not generally the case for singular count nouns, as (5) shows.

(4) a. a team of players

b. *a team of player

c. a group of children

(GROUP)

d. *a group of child

e. a committee of scholars

f. *a committee of scholar 
(5) a. *a piece of cookies

b. a piece of cookie

c. *a table of woods

d. a table of wood

e. a slice of pizza

f. *a slice of pizzas

When considering the proposed swarm nouns, as in (6), we find that they behave like as bona fide group nouns do under Barker's test. This supports their classification together under the macro-category I am calling collective nouns.

(6) a. a grove of trees

b. *a grove of tree

c. a horde of barbarians

(SWARM)

d. *a horde of barbarian

e. a bouquet of flowers

f. *a bouquet of flower

If we borrow Barker's definitional criterion for group nouns, though, and use it for collective nouns as a class, new criteria are needed for distinguishing those nouns with group reference and those with swarm reference. There are actually most likely a variety of subtypes of collective nouns, and so a simple binary classification system will not be sufficient. Instead, I propose that nouns having swarm reference denote individuals that share three core properties. In particular, (i) a swarm's constituent individuals have a (contextually specified) large cardinality, (ii) a swarm's constituent individuals must occupy a circumscribed region of space, and (iii) a swarm individual is available for spatial predication based on the configuration of its constituent individuals. A noun is a swarm noun just in case it passes the tests for these properties, while canonical group nouns will fail the relevant tests. ${ }^{5}$ In addition to the cardinality and spatial conditions, I will also show that the plurality that constitutes a swarm individual can, for some swarm nouns, be more difficult to access than with a group individual. While this will not be a definatory property of swarm nouns, since not all nouns satisfying the three properties above behave uniformly in this way, it will be core property of swarms in the event-domain. This difference will be explained in virtue of ontological differences between events and individuals.

The behavior of collective nouns with respect to plural pseudopartitives shows that nouns of both categories appear to denote individuals constituted by a plurality. I need to show that these higher-order individuals denoted by canonical group nouns have different

\footnotetext{
${ }^{5}$ This leaves open the possibility that some collective nouns only pass a subset of these tests. One example might be platoon, which while otherwise behaving as a canonical group noun, specifies that its constituent individuals have a specific cardinality (though not a contextually specified one like swarm nouns). Its existence does not pose a problem for isolating swarm nouns as a class, though. It would be similar to how accomplishment verbs partially overlap in their properties with achievements and activities, while still being a separate lexical class.
} 
properties than those denoted by the proposed swarm nouns. To begin doing this, the first core property of swarm reference concerns the cardinalities of the pluralities that compose collective individuals. Swarm individuals cannot be constituted by a simple plurality, but must instead have a large (contextually specified) number of constituent individuals. To see this, consider the behavior of pseudopartitives that directly specify the cardinality of the plurality that constitutes the collection. When the pseudopartitive specifies mere nonatomicity, as in (7b-7f), the swarm nouns are infelicitous. This is not the case with groups nouns, like (8), which can be felicitously constituted by two individuals.

(7) a. John planted a grove of thirty redbud trees.

b. \# John planted a grove of two redbud trees.

c. A horde of five-hundred undead attacked.

d. \# A horde of two undead attacked.

e. A swarm of two-hundred bees attacked the beekeeper.

f. \# A swarm of two bees attacked the beekeeper.

(8) a. Doubles tennis pits one team of two players against another.

b. The board convened a select committee of two VPs.

(GROUP)

c. Bill needs to learn to cook for a family of two.

d. Right now we can only seat a group of two.

The second core property of swarm reference builds on the first. Swarms must not only be constituted by a sufficiently large number of individuals, but those individuals must occupy the same region of space. This is testable by considering the spatial entailments that swarm nouns make about their constituent individuals. In particular, swarms can cease to exist if their constituent individuals are moved to new locations, while the individuals denoted by group nouns do not have this property. This can be shown by truth-value judgments in contexts like the following. Examples (9a-10a) are entailed in the given context, while examples (11a-12a) are not.

(9) Someone takes the each flower from the bouquet and places it in a different room of the house. $\Rightarrow$

a. The bouquet no longer exists.

(SWARM)

(10) The beekeeper catches each bee in the swarm and puts it in its own hive. $\Rightarrow$

a. The swarm no longer exists.

(SWARM)

(11) Each member of the family moves to a different country for work. $\nRightarrow$

a. The family no longer exists.

(GROUP) 
(12) Each member of the committee travels to a different state to visit family. $\nRightarrow$

a. The committee no longer exists.

(GROUP)

The pattern shows that swarm-nouns generate non-trivial entailments about the spatial configuration of the swarm's constituent individuals. Canonical group nouns, in contrast, do not generate these kinds of entailments about the individuals they denote. In particular, it seems that group nouns denote individuals whose existence does not depend on the spatial configuration of its members.

The final core property of swarm nouns extends the first two. I have shown that swarm nouns denote individuals that are constituted by a contextually specified large plurality that occupies a circumscribed region of space. It can be further shown that a swarm individual can bear spatial properties based on the configuration of its constituent plurality in the region of space it occupies. This is not true for group nouns. This can be shown by considering a subclass of those predicates called stubbornly distributive by Schwarzschild 2011, which can only be predicated of atomic individuals (i.e., they cannot be predicated of plural or mass individuals). In particular, I want to focus on those predicates, like wide or circular, which express spatial properties. First, note that while these properties could in principle be predicated of a plurality, they cannot be.

(13) Suppose that some soccer players are standing around in a circle.

a. \#Those players are circular.

(14) Suppose that a large number of professors are standing in middle of a hotel lobby and you have to walk quite a ways to get around them.

a. \#These professors are wide!

What these examples with plural nouns show is that even when a plurality is arranged in the correct configuration, it cannot fall in the extension of a spatial stubbornly distributive predicate. When we move to group nouns, we see the exact same behavior. The spatial configuration of the individuals that constitute a group do not allow the group to be in the extension of a spatial stubbornly distributive predicate.

(15) Suppose that some soccer players are standing around in a circle.

a. \#That team is circular.

(GROUP)

(16) Suppose that the members of a committee are standing in middle of a hotel lobby and you have to walk quite a ways to get around them.

a. \#This committee is wide!

(GROUP)

Swarm nouns pattern differently than both plural count nouns and group nouns. Swarm individuals can satisfy spatial stubbornly distributive predicates, and they do so in virtue of the configuration of the plurality that constitutes the swarm. 
(17) Suppose that a florist has arrange the flowers so that they form a tight circle.

a. The bouquet is circular.

(SWARM)

(18) Imagine you are walking around large grove of pine trees and and it is taking quite awhile to get around.

a. Wow, this pine grove is wide.

(SWARM)

Supporting the judgments in (17-18) are the many naturally occurring examples one can find with swarm nouns and spatial stubbornly distributive predicates like wide, circular, and long. Crucially, in each case, it is easy to tell from context that entire configuration is meant to have the shape in question, not each individual that constitutes the plurality, which is the only ready one gets with plural count nouns or group nouns.

(19) a. The grove was long. Winthrop walked steadily. He reached at last the end of the white-blooming forest.

b. ... I improvised and used water, making sure that the bouquet was wide enough to hold it in place in the vase.

c. On unstressed agar, the rate of spreading is the same in all radial directions and the swarm is circular, ...

d. The bouquet was circular with light purple hydrangeas encircled by yellow daisies interspersed with dark purple daisies.

e. ... a shower could be expected if the meteor swarm was wide enough to stretch all the way to Earth.

Examples (17-18) and (19) illustrate that assessing the spatial properties of a swarm means considering the total configuration of the individuals that constitute it. In this way, swarm nouns are different than group nouns under spatial predication. It confirms that while swarms, just like groups, are constituted by a plurality, they stand in a different relation to that plurality than do groups.

With these core properties in hand, we can consider a property that not all swarm nouns share, but which does, for the relevant nouns, distinguish them from canonical group nouns. In particular, if swarm nouns denote individuals that are constituted by a plurality, we might expect that plurality to be grammatically accessible. We find, though, that the plurality constituting swarm individuals is not always so.

First, consider the behavior of plural anaphora. Canonical group nouns freely license plural anaphora (some preferentially so), as in (20), but some swarm nouns only allow singular anaphora, which is illustrated in (21).

(20) a. The family is in the backyard. They are by the river.

b. The team is in the backyard. They are by the river.

c. The committee is in the backyard. They are by the river.

d. The group is in the backyard. They are by the river.

(GROUP) 
(21) a. The grove is in the backyard. \#They are / It is by the river.

b. The bouquet is in the backyard. \#They are / It is by the river.

(SWARM)

While swarm nouns like grove and bouquet seem to only allow singular anaphora, the facts are more complex for nouns like swarm and horde. One can find attested examples with these nouns licensing either plural or singular anaphora, as in the following examples from COCA (Davies 2008).

(22) a. The swarm would be swept away if it came into the river.

b. I suspected that the reason for the swarm's inactivity was that its sources of nectar were so few that foraging would simply...

(23) a. My guess is the swarm will mate, dig down to wherever they lay their eggs, then die.

b. This simple repetitive movement helps stabilize the swarm; once gathered by currents, they are less likely to veer off in all...

(24) a. As quickly as the horde had appeared, it dispersed, leaving behind only a small crew who methodically began to secrete a sticky substance...

b. The horde closed in, and its sweaty heaving mass pressed us together so tightly we could have had simultaneous grand mal seizures and no one would have known until last call.

(25) a. ...looking at Denny, at the table, anywhere but at the horde coming in the door. Even when she looked away, she heard them:

b. On the second floor you invariably come across a horde jockeying and elbowing as close as they can get to a bulletproof, air-conditioned showcase.

The inability of some swarm nouns to license plural anaphora, when group nouns uniformly do, suggests that the plurality that composes a swarm is not always as grammatically accessible, though this is not a uniform property of swarm nouns, as the behavior of swarm and horde shows.

Further considerations support this generalization. For instance, collective predicates, like look alike or look good together are ungrammatical with singular arguments and instead require one that is plural. ${ }^{6}$

\footnotetext{
${ }^{6}$ It is necessary to restrict the generalization to collective predicates that do not exclusively make use of spatial notions, which can be felicitously predicated of swarm individuals, as shown in the following examples.

(26) a. The grove encircled a small spring.

b. The swarm gathered at the entrance to the hive.

c. Mary separated the bouquet.
} 
(27) a. The trees look alike.

b. The flowers look alike.

c. The trees look good together.

d. The flowers good together.

(28) a. \# The tree looks alike

b. \# The flower looks alike.

c. \# The tree looks good together.

d. \# The flower looks good together.

These predicates thus provide a test for plural reference. As we might expect from their ability to license plural anaphora, group nouns are felicitous with them.

(29) a. The family looks alike.

b. The team looks alike.

c. The family looks good together.

d. The team looks good together.

(GROUP)

In contrast, those swarm nouns that are unable to license plural anaphora are judged infelicitous with these collective predicates. This is further evidence that they do not make a plurality grammatically accessible. If they did, we would expect that this plurality-of trees in the case of grove and of flowers in the case of bouquet-should meet the needs of these predicates as in (27).

(30) a. \# The grove looks alike.

b. \# The bouquet looks alike.

c. \# The grove looks good together.

d. \# The bouquet looks good together.

(SWARM)

As with plural anaphora, the nouns swarm and horde show variation on this test. Many examples with these nouns with collective predicates are infelicitous. That said, one can find attested examples, as in (31-32), with collectivizing adverbials like together.

All these predicates, though, involve exclusively spatial notions. For instance, encircle requires the object to stand inside some spatial extent defined by the subject. Similarly, gather requires a plurality of individuals to be closer together at the end of an event than at the start of it, while separate requires the opposite. This fits well with our intuition that swarms are defined in terms of their spatiotemporal extent. Collective predicates that requires a spatially extended individual are grammatical with all swarm nouns, while others, which need to access the individual members of a swarm are not always able to do so. 
(31) a. Each turn the swarm traveled together, fanning out so that Whisper could not reach the outside of my group with a de-cloak.

b. When traffic jams happen or robots go off course, the swarm works together to solve the problem.

(32) a. The logic of the zombie, how it infects and how the horde works together was spooky.

b. Because the horde travels together you are hard pressed to attack it...

This behavior is expected of horde and swarm, given their ability to license plural anaphora. In both cases they can pattern like a plural count noun (or a group noun for that matter) in certain cases where the grammar requires.

In these observations, collected in Table 1, we already have enough contrasts to begin constructing an analysis of the group/swarm distinction. To summarize, in virtue of accepting a plural pseudopartitive, both group nouns and swarm nouns pattern together as collective nouns. Swarm nouns are then distinguished from group nouns along three parameters. First, swarm individuals are composed of a plurality of individuals with a contextually specified high cardinality. Second, swarm individuals exist in virtue of the spatial arrangement of their constituent individuals. Third, swarm individuals can bear spatial properties in virtue of the configuration their constituent individuals. The individuals that satisfy group nouns do not have these properties. Finally, because both swarm and group nouns are related to a plurality, an immediate question is whether that plurality is grammatically accessible. Here there is actually a split. Group nouns can license plural anaphora and satisfy collective predicates, and so can a subset of swarm nouns. Other swarm nouns, though, denote individuals whose constituent pluralities not immediately accessible.

\begin{tabular}{|l|l|l|}
\hline & SWARMS & GROUPS \\
\hline plural pseudopartitives & $\checkmark$ & $\checkmark$ \\
\hline only large constituent pluralities & $\checkmark$ & $\boldsymbol{X}$ \\
\hline spatial existence entailments & $\checkmark$ & $\boldsymbol{X}$ \\
\hline support spatial predicates & $\checkmark$ & $\boldsymbol{X}$ \\
\hline can expose a plurality & mixed & $\checkmark$ \\
\hline
\end{tabular}

Table 1: SWARMS vs GROUPS

The analysis proposed in the following section will be able to account for these differences between group and swarm nouns, as well as the variation within the swarm nouns with respect to their ability to behave like a plural count noun. Before presenting this analysis though, I want to clarify a few points about the grammatical status of swarm reference.

I assume that the distinction between group nouns and swarm nouns is a lexical one. It is like the distinction between between verbs of different aktionsart classes, which are classified by groups of tests akin to those in Table 1. As with lexical aspect, this leaves open how the classes are analyzed. For instance, we could use a many-sorted domain 
(e.g., de Swart 1998), a set of binary features (e.g., Verkuyl 1972), or a set of different schematic denotations (e.g., Dowty 1979). I take the last route, where templates constrain possible lexical meanings, and thus capture generalizations over the meanings of lexical classes. The rest of this section will be focused on creating such a template for expressions with swarm reference.

To start, the next section introduces the account of group nouns in Barker 1992, which I borrow wholesale because it provides a nice point of contrast for my analysis of swarms. Barker argues that group nouns denote group individuals that have no parts, but are associated with a plurality by a function mapping individuals to their "members". We can think of this being one way to construct higher-order individuals. In $\$ 2.2$, I propose that the swarm nouns identified in this section illustrate another way to construct higher-order individuals. In particular, swarms individuals are atomic individuals that are linked up with a plurality via a spatial trace function. The spatial trace and Barker's 1992 membership function play similar roles in individuating collective entities-they relate an atom to a plurality - but they do so in slightly different ways. This will account for cases where swarm nouns and group nouns diverge. Crucially, though, nothing will preclude a swarm individual from also having members. I propose that this is the case for nouns like horde, which have the properties of a swarm noun, but can also expose a plurality like group nouns. A noun like horde will denote a swarm individual that is defined in terms of the spatiotemporal properties of a plurality, but that plurality will be additionally accessible as the members of the horde via the membership function.

\subsection{Barker's Account in Brief}

Barker 1992 says that singular group nouns, like singular count nouns more generally, denote atoms in the lattice of individuals with respect to the 'part of' relation. ${ }^{7}$ While they have no parts, they are distinguished by having a plurality of "members", where the members of an individual are given by a function. Formally, the membership function $f$ is an endomorphism on the domain of individuals. ${ }^{8}$ In this analysis, group nouns just denote atoms that are mapped to pluralities under $f$. In figure 1, adapted from Barker 1992: ex. 17, the arrows represent a partial membership function $f$ for the lattice. For instance, $b$ and $c$ are normal singular entities because they are atoms and have themselves as members. The sum $b \oplus c$ is a normal plural entity because it is non-atomic and has a plurality for its members (namely the sum of its parts). Finally, $a$ is a group because it is atomic, but is mapped to a plurality under $f$, namely the sum of its members $a$ and $b$.

While I do not present all of Barker's results in detail, the analysis provides the power necessary to capture the core properties of group nouns. The idea is that they behave like singular count nouns for those processes that are sensitive to atomicity, like verb agreement. In contrast, they behave like plural count nouns in those constructions that have access to $f$, which can retrieve the pluralities associated with group atoms. For instance, suppose that collective predicates are distinguished in having no atomic individuals in

\footnotetext{
${ }^{7}$ The domain of individuals $\mathfrak{D}_{e}$ is taken to be a complete atomic Boolean algebra without a zero element. The join operator $\oplus$ on $\mathfrak{D}_{e}$ forms sums and induces a unique partial order $\leq$. Atoms are minimal elements with respect to $\leq$.

${ }^{8}$ Recall that an endomorphism is a function from a domain to itself that is structure-preserving, i.e., $f(a \oplus b)=f(a) \oplus f(b)$.
} 


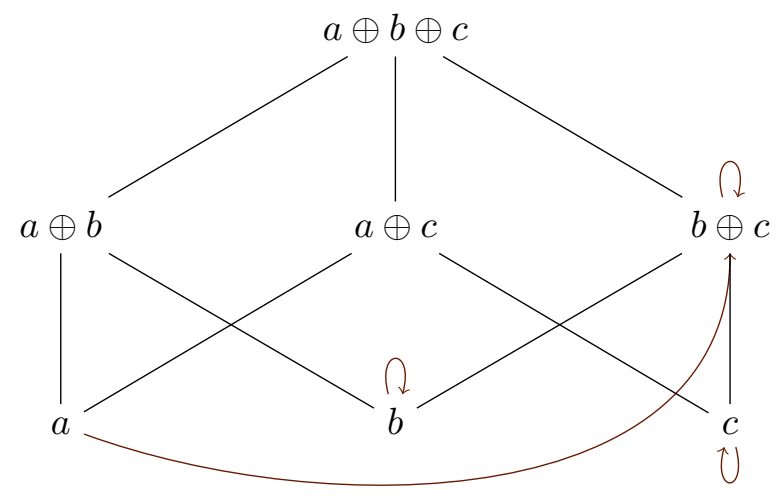

Figure 1: Atoms, Groups, and Pluralities

their extension. Furthermore, suppose following Barker 1992 that collective predicates like (33) can pass their argument through $f$.

(33) looks alike $\rightsquigarrow \lambda x[\operatorname{LOOK}$.ALIKE $(f(x))]$

(34) a. The trees look alike.

b. The family looks alike.

(GROUP)

c. *The tree looks alike.

This immediately captures the pattern above repeated from (27-29) for plural count nouns, group nouns, and singular non-group nouns. If group nouns denote atomic individuals that are mapped to a plurality under $f$, when (33) is passed a group entity, like the one denoted by that family in (34b), $f$ will map that individual to the sum of its members, a plurality that can be in the extension of the collective predicate. At the same time, because $f$ maps pluralities of non-group individuals to themselves, (34a) is predicted to be felicitous. The subject those trees denotes a plural individual that $f$ will map to itself, and plural individuals can be in the extension of collective predicates. Finally, the membership function will do no good for (34c). Non-group atoms are mapped to themselves under $f$, but there are no atomic individuals in the extension of collective predicates. Thus, (34c) is predicted to be infelicitous.

Extending this account to swarm nouns requires recognizing the split between those swarm nouns like horde or swarm that are able to expose a plurality from those like grove or bouquet which cannot. If supporting collective predicates (or licensing plural anaphora for that matter), requires being related to a plurality by $f$, as Barker 1992 proposes, then we must say that the individuals in the extension of swarm and horde are related to a plurality via $f$, while those in the extension of bouquet and grove are not. This will account for the contrast between the two varieties of swarm nouns illustrated in (29-30) for collective predicates like look alike. Those that pattern with group nouns and plural count nouns on tests of plural reference will expose a plurality via $f$, while those that 
do not not will not. Note, though, that allowing some swarm nouns to denote atomic individuals with a plurality of members, as given by $f$, is not sufficient for understanding all of the properties of swarm nouns and their differences from canonical group nouns. In particular, none of the spatial or cardinality properties follow. Even more pressing, if the swarm individuals denoted by grove and bouquet are not related to a plurality of members under $f$, then we need another account of how they are related to the pluralities of trees and flowers that intuitively compose them. The next section develops just such an analysis, which will account for the similarities and differences between groups and swarms, but also easily extend to event-internal pluractional verbs. Additionally, the analysis will allow for some swarm individuals, like those in the extension of horde, to be also related to a plurality of members under $f$ like the group individuals that satisfy canonical group nouns.

\subsection{Analyzing Swarms}

Consider again a swarm noun like grove. We have the strong intuition that the individuals it denotes are composed of a plurality, yet these nouns can be grammatically distinguished from both plural count nouns and other collective nouns. The situation is reminiscent of superordinate mass nouns like furniture and their relation to the count nouns that they categorize. While any individual in the model that meets the criteria for being predicated of chair also meets the criteria for being predicated of furniture, the grammar treats individuals packaged as furniture completely differently. (They are uncountable, for instance.) Similarly, while an individual that falls in the extension of a predicate like grove would seemingly fall in the extension of trees (though not tree, crucially), the grammar treats individuals packaged as groves differently. We want to know what sort of packaging is at issue and how to model it formally. The primary conclusion of the previous sections is that it must not be identical to that which we see with group nouns. We cannot only relate swarms to their constituent individuals via the endomorphism $f$, which encodes our intuitive notion of membership.

To meet the empirical challenges that motivate this conclusion, this section develops the idea that swarms are related to their constituent individuals via a structured form of spatiotemporal superposition. This will explain why the grammar treats swarms differently than both count pluralities and groups, and lay the foundation for analyzing eventinternal pluractionality as this same distinguished subtype of collective reference. First, though, I want to make explicit a few core formal assumptions about space and time.

In addition to the domain of individuals $\mathfrak{D}_{e}$, I assume, building off of Bach 1986; Hinrichs 1985; Link 1998, that there are domains of eventualities, times, and regions of space- $\mathfrak{D}_{\varepsilon}, \mathfrak{D}_{\tau}$, and $\mathfrak{D}_{\sigma}$, respectively—which also have internal structure. For simplicity's sake, I take them to have the same part-whole structure as the domain of individuals, that is, they are complete atomic Boolean algebras without a zero element. ${ }^{9}$ When it is

\footnotetext{
${ }^{9}$ If one is worried about the event lattice being complemented, we can relax this assumption without changing the analysis. The same can be said for the assumption that there are atomic stretches of time and regions of space. I am merely assuming this for formal simplicity, and do not mean to make any ontological claims about natural language. The analysis as presented, though, does require the existence of atomic events to account for missing distributive readings with event-internal pluractionals. Making the event lattice atomless will thus mean altering parts of $\$ 3$. It would be possible, though, to make such alternations while
} 
not clear from context, I will use $\leq_{\varepsilon}, \leq_{\tau}$, and $\leq_{\sigma}$ for their intrinsic ordering relations. Usually, though, which is meant will be clear from what is ordered. In particular, I will use $e, e^{\prime}, \ldots$ as variables for events, $t, t^{\prime}, \ldots$ for times, and $s, s^{\prime}, \ldots$ for spaces. The big picture is that by structuring times and spaces in this way, we can immediately deal with notions of temporal and spatial containment, overlap, and disjointness. ${ }^{10}$ What we cannot easily model, though, are topological notions like connectedness, which will be necessary for analyzing swarm reference. To do this, I follow Krifka 1998 and provide a symmetric relation $\infty$ that holds between entities that are externally connected, i.e., adjacent entities. ${ }^{11}$ As with the parthood relation, I assume an adjacency relation for each domain disambiguated by context. Adjacency must satisfy the following two axioms. The first says overlapping ${ }^{12}$ elements cannot be adjacent. The second says that if an element is adjacent to the part of something, it is either also part of that thing or adjacent to it.

$$
\forall x, y[x \infty y \rightarrow \neg O(x, y)]
$$

$$
\forall x, y, z[x \infty y \wedge y \leq z \rightarrow x \infty z \vee O(x, z)]
$$

Additionally, I define a weaker version of adjacency, which must also satisfy the above axioms, holding between elements that are proximally adjacent given some contextually specified distance. That is, given a distance function $d-$ a function from the Cartesian product of a set to the non-negative numbers-proximal adjacency is defined as follows, where $n$ is contextually supplied. Additionally, we clearly want bona fide adjacency to entail proximal adjacency for all values of $n$, which is made explicit in (38).

$$
\begin{aligned}
& x \infty^{\text {prox }} y:=0<d(x, y) \leq n \\
& \forall x, y\left[x \infty y \rightarrow x \infty^{p r o x} y\right]
\end{aligned}
$$$$
\text { (Proximally Adjacent) }
$$

With these basic domains and their structure in place, we can make an easy extension to model the intuition that events occur in time and space. This is done with trace functions in the standard way. The temporal trace function $\tau: \mathfrak{D}_{\varepsilon} \mapsto \mathfrak{D}_{\tau}$ is a partial function from

preserving the intuition behind the analysis. In what follows, when I make reference to atomic entities in formulas, I have included a footnote describing how to avoid their use, though perhaps sacrificing perspicuity.

${ }^{10}$ This is not the only structure we assume for these domains. Otherwise, we would incorrectly treat, events, stretches of times, and regions of space as indistinguishable. For instance, to capture the fact that times are naturally ordered by precedence in ways that regions of space are not, we want to assume a linear order $\preccurlyeq$ on the atoms in $\mathfrak{D}_{\tau}$, and then use it to induce a strict temporal precedence order $\prec$ on all of $\mathfrak{D}_{\tau}$. See, for example, Landman 1991; Link 1998 for how to do so.

${ }^{11}$ Another option would be to define externally connected in full-fledged mereotopology (Casati \& Varzi 1999; Smith 1996). I do not take this route because, given the data at hand, it is not necessary to express the varieties of connectedness that come with these theories beyond external connection. Note, though, that Grimm 2012 develops an analysis in mereotopology of a certain class of morphologically distinguished mass nouns in languages like Welsh and Dagaare, which denote spatially clustered individuals. While the empirical phenomena treated here are quite different (not involving mass nouns, for instance), Grimm 2012: ch. 4 inspires my treatment of spatial clusters.

${ }^{12}$ Two entities overlap just in case they share a part, i.e., $O(x, y):=\exists z[z \leq x \wedge x \leq y]$ 
the domain of events to the domain of times, and the spatial trace function $\sigma: \mathfrak{D}_{\varepsilon} \mapsto \mathfrak{D}_{\sigma}$ is a partial function from the domain of events to regions of space. ${ }^{13}$ We require both $\tau$ and $\sigma$ to be complete sum-homomorphisms (see Champollion 2010 for a defense of these structures), that is, $\tau(e) \oplus \tau\left(e^{\prime}\right)=\tau\left(e \oplus e^{\prime}\right)$ and $\sigma(e) \oplus \sigma\left(e^{\prime}\right)=\sigma\left(e \oplus e^{\prime}\right)$. Finally, trace functions must respect adjacency structures-i.e., $e \infty e^{\prime}$ holds if and only if $\tau(e) \infty \tau\left(e^{\prime}\right)$ and $\sigma(e) \infty \sigma\left(e^{\prime}\right)$ where defined. This means that $\infty$ in the event domain means total spatiotemporal adjacency. We can can of course talk about different notions of adjacency between events in terms of their traces. For instance, we can talk about two events being temporally adjacent when $\tau(e) \infty \tau\left(e^{\prime}\right)$ holds, even if it turns out that $e \infty e^{\prime}$ does not.

While these trace functions play a major role in $\S 3$, they are introduced now in order to contextualize the less common idea of defining spatial traces for individuals, which I pursue now. It is clear that something like this is necessary for analyzing the non-trivial spatial component of swarm nouns. We want to be able to say that a plurality of trees is a grove or that a plurality of flowers is a bouquet, in part, because those trees and flowers fill a circumscribed region of space. It is this location that is the spatial trace of the grove or bouquet. That said, we cannot just immediately extend the notion of event trace to the individual domain. The reason is that individuals are not identified with their spatial extent in the same way that events are. Consider, for instance, an event of John walking to the store. We have no problem saying that its spatial trace is all the space in which that event takes place. But what should be the spatial trace of John? It seems wrong to say that his spatial trace is every location he ever occupies. Instead, we want to say that an individual's spatial trace is only defined relative to some period of time-that is, the space the individual occupies over that time. Intuitively, the unmarked case of an individual's spatial trace is its spatial extent at an instant. For this reason, I propose that the individual spatial trace $\varsigma$ is a function from instants and individuals to spatial extents. That is, $\varsigma: \mathfrak{D}_{e} \times \mathfrak{D}_{\tau}^{\circ} \mapsto \mathfrak{D}_{\sigma}$, where $\mathfrak{D}_{\tau}^{\circ}$ are the atomic times, or instants, in $\mathfrak{D}_{\tau}{ }^{14}$ Thus, we can use $\varsigma$ to give the spatial extent of an individual at a particular instant. As with event traces, individual spatial traces must respect adjacency structures. That is, at a particular instant, $a \infty b$ holds if and only if $\varsigma(a) \infty \varsigma(b)$. While we could cumulatively close $\varsigma$ in order to track an individual's path in space over time, this will not be necessary in the analysis that follows. In fact, I will usually suppress the individual trace's time argument, taking it to be some contextually salient instant.

These background assumptions set the stage for analyzing swarm nouns. Thinking back to the analysis of group nouns in Barker 1992, the central idea is to treat groups as atomic individuals that are associated with a plurality via the membership function. I propose that swarms are formally similar, except that they are related to a plurality via the spatial trace function. In particular, they denote atomic individuals whose spatial trace can be partitioned in a way that satisfies a series of properties: (i) each element in the partition is the spatial trace of an individual satisfying some lexically given predicate (this is how swarms are linked up with a plurality of individuals), (ii) the partition must have a large

\footnotetext{
${ }^{13}$ Trace functions are partial because some eventualities, especially states, arguably do not take place in space and time.

${ }^{14}$ If we were working in a system without atomic times, we could substitute here, instead of instants, contextually specified short intervals.
} 
cardinality, and (iii) the elements of the partition must be clustered. ${ }^{15}$ The most difficult aspect of this analysis is defining clusters. Example (39) defines a predicate for clustered sets of individuals, given two parameters: (i) a number $n$ of elements each element in the cluster must be near, and (ii) an adjacency relation $A$ specifying nearness. ${ }^{16}$

$$
\operatorname{cluster}_{A}^{n}(X):=\forall x \in X \exists Y \subseteq X[|Y|=n \wedge \forall y \in Y[A(x, y)]]
$$

For instance, in the simplest case where $n=1$ and the adjacency relation is $\infty$, a clustered set is one where each element is externally connected to some other element in that set. This is consistent with many spatial configurations, including a line. To rule out lines, and induce bunching, $n$ can be increased. For instance, if $n=3$, each element in the set would have to be externally adjacent to at least three others. Changing the adjacency relation to $\infty^{\text {prox }}$ would then introduce a second parameter, allowing each element of the cluster to be at most a certain distance from the three other elements it must be proximally adjacent to. My proposal is that expressions with swarm reference all make use of this predicate cluster ${ }_{A}^{n}$, but values of $n$ and $A$ vary and are lexically set. For instance, bouquet arguably requires its constituent flowers to be touching, along with some amount of bunching, which means it would use $\infty$ as its adjacency relation and set $n \neq 1$. In contrast, archipelago can hold of a string of islands of proximately adjacent islands, and so would use $n=1$ and $\infty^{\text {prox }}$, where the latter would tolerate distances that are quite large. One can also find nouns, like queue or traffic jam, that stand in between, tolerating some bunching requiring fairly short distances for $\infty^{\text {prox }}$.

Using the definition in (39), along with the definitions of a partition in (40) and a fine partition in (41), the meaning for a noun like grove is provided in (42).

$$
\operatorname{partition}(\mathrm{P}, x) \text { iff }
$$

a. $\bigoplus \mathrm{P}=x$

b. $\forall x(x \in \mathrm{P} \rightarrow \neg \exists y(y \in \mathrm{P} \wedge O(x, y)))$

'P partitions $x$ iff the elements of $\mathrm{P}$ sum to $x$ and no elements of $\mathrm{P}$ overlap.'

$$
\text { fine }_{\mu}(\mathrm{P}) \text { iff every } x \in \mathrm{P} \text { is very small on measure } \mu \text {, but } \bigoplus \mathrm{P} \text { stands out on } \mu .^{17}
$$

\footnotetext{
${ }^{15}$ The analysis shows clear parallels with that developed by Champollion 2010 for a variety of distributivity phenomena under the heading Strata Theory. The major differences are that (i) my analysis must use partitions, not covers, and (ii) it quantifies over the parts of an entity's trace, not the parts of an entity directly. An important area of future research is to see whether it is possible to partially unify in some overarching theory the phenomena presented here with those discussed his work.

${ }^{16}$ This is similar to how computational biologists model swarming behavior in animals, which usually involves parameters for individuals' preferred distance to some number of neighbors (see Parrish, Viscido \& Grünbaum 2002 for an overview).

${ }^{17}$ There are various ways to formalize this notion of contextually specified comparative smallness. Here is one. Let $\mu$ be a measure function-a function from entities to degrees on scale-defined for the partitioned object. For example, if we partition a space, $\mu=$ area would map elements of $\mathfrak{D}_{\sigma}$ to degrees on a scale with dimension area. Now we say that a partition satisfies fine just in case for all $x$ in the partition, $\mu(x)<$ $d_{\text {small }}<d_{\text {std }} \leq \mu(\oplus \mathrm{P})$. If this condition holds, it follows that there must be many elements of the partition, each of which is very small, and very small compared to the partitioned object.
} 


$$
\begin{aligned}
\text { grove } \rightsquigarrow \lambda x \exists \mathrm{P}[ & \operatorname{atom}(x) \wedge \varsigma(x)=\varsigma(f(x)) \wedge \\
& \quad \text { partition }(\mathrm{P}, \varsigma(x)) \wedge \text { fine }_{\mu=\text { area }}(\mathrm{P}) \wedge \operatorname{cluster}_{\infty^{\text {prox }}}^{4}(\mathrm{P}) \wedge \\
& \forall s \in \mathrm{P} \exists y[\varsigma(y)=s \wedge \operatorname{TREE}(y)]]
\end{aligned}
$$

The translation in (42) has been split into three lines for perspicuity. The first says that grove applies to atomic individuals whose spatial trace is the same as the individual given by the membership function. In the case of grove, this condition is trivially satisfied, since as established above, this swarm noun cannot expose a plurality and so $f$ will map the members of grove to themselves. The second line says that the relevant atoms are those whose spatial trace can partitioned into small parts, each of which must be proximally adjacent to at least four other spatial traces in the partition. ${ }^{18}$ The final line requires that each element of the partition is the spatial trace of a tree. This last condition is given as part of the lexical semantics of grove and will differ across various swarm nouns. ${ }^{19}$ Not only does (42) capture the intuitively correct satisfaction conditions for a predicate like grove, it makes a series of correct predictions about the distribution and interpretation of nouns that denote swarm individuals. That said, it is important to preface this discussion by noting that I take the template in (42) to be a kind of lower bound for the semantics of swarm nouns. There can be additional conditions imposed by particular lexical items. For instance, a bouquet is not merely a spatially clustered group of flowers, but the cluster cannot be too large and the flowers themselves must be pointed in the same direction. In what follows, I will be focused on those core properties captured by (42) that swarm nouns share.

First, the existence of a grove entails the existence of a plurality of trees, just as other collective nouns, like committee, entail the existence of a plurality of members. Additionally, (42) correctly accounts for the fact that swarms have a large number of constituent individuals, not just a plurality, as the contrast in (7) requires. That is, while a team, committee, or family can felicitously have only two members, swarms always need many more. Two trees cannot form a grove. This entailment follows from the definition of a fine partition and the fact that an individual's spatial trace is given by a function, which cannot map the same tree to two different elements of the spatial partition. To see this, consider the fact that if the partition of a space has only two parts, even if we try to minimize their individual sizes, neither will be very small compared to the whole. We can only ensure that every element of the partition is very small relative to the whole if we have a partition with a large cardinality. But then, because $\varsigma$ cannot map the same individual at the same time to two different regions of space, (42) requires the cardinality of the trees that compose the grove to equal the cardinality of the spatial partition. The result is that swarm nouns like grove, horde, and bouquet are correctly predicted to require, not just a simple plurality of constituent individuals, but a plurality of large cardinality.

The second core difference between swarm nouns and group nouns concerns the existence criteria for the kinds of individuals they denote. When a committee finishes meeting

\footnotetext{
${ }^{18}$ Here I have selected 4 for the numerical parameter because it is not obviously wrong, and is additionally a number commonly used to model swarm behavior in nature (Parrish, Viscido \& Grünbaum 2002). The core idea is that groves should be, if not circular, roughly oblong, which is consistent with this version of the cluster predicate. Further research is needed to precisely dial in the parameters for all such lexical items.

${ }^{19}$ In the final section, $\S 4$, I present examples from Romanian in which swarm nouns are derived. In these cases, the lexical predicate in the schema in (42) is provided compositionally, not lexically.
} 
and its members go home, the committee does not dissolve. Committees are not defined in terms of the spatiotemporal properties of the individuals that constitute them. They are defined in terms of membership and shared goals. The same is true for committees, teams, and families. Swarms are different. If all of the warriors in a horde go home, the horde ceases to exist. Similarly for groves and bouquets. If we take the flowers in a bouquet and place them around the room, the bouquet is no more. Swarms are clearly defined in terms of the spatiotemporal properties of their members. ${ }^{20}$ They must fill some region of space. This property of swarms is immediately captured in the analysis in (42), which is based on the predicate of clusters defined in (39). Given the particular lexical setting of the two core parameters, a grove's spatial trace must be able to be partitioned in such a way that each member is the trace of a tree, and no such member is too distant from other members. This is what generates the spatial entailments that accompany swarm nouns.

The third property defining swarm individuals is that they can satisfy spatial stubbornly distributive predicates, and do so in virtue of the configuration of their constituent individuals. The formula (42) ensures that this is possible. First, note that all swarm individuals must have a spatial trace, and so are in principle available for spatial predication. Second, swarm nouns denote atomic individuals. If nouns like wide or long, following Schwarzschild 2011, can only be predicated of atomic individuals, then swarm individuals meet this requirement. Finally, the spatial trace of swarm individuals is directly given by the configuration of their constituent individuals. In particular, in (42), the spatial trace of the grove must be the sum of the traces of a plurality trees. Taking these three considerations together, we understand why a grove could satisfy a predicate like wide, and do so in virtue of the configuration of its constituent individuals.

To account for how swarm nouns contrast with canonical group nouns on this point, first recall that when spatial stubbornly distributive predicates are predicated of a plural count noun, the only interpretation is that the atomic parts have the property in question. That is, a sentence like 'The players are wide' can only mean that the individual players are wide, not that they are arranged in a wide configuration. Now recall that group nouns with spatial stubbornly distributive predicates have only the same reading, e.g., 'The team is wide' can only mean that the individual members of the team are wide. This equivalence supports an analysis that simply says that group nouns, unlike swarm nouns, denote atomic individuals without a spatial trace. Thus, the only way to use a group noun with a spatial predicate is to predicate it of the members of the groups in its extension-e.g., $f(x)$ for the group $x$. In the case of a group noun, though, $f(x)$ will be a plurality and so we predict the observed equivalency with the plural count noun under spatial stubbornly distributive

\footnotetext{
${ }^{20}$ In this way, swarm nouns are similar to those that Krifka 1990 calls phase nouns (first discussed in Gupta 1980). Such nouns, like passenger, are true of an individual only over a stretch of time. In the case of passenger, the stretch of time must correspond to the temporal trace of an event in which that individual travels. While there are similarities between phase nouns and swarm nouns given their spatiotemporal dependence, there are important differences that prevent a straightforward unification. In particular, phase nouns are dependent on an event. Krifka 1990 analyzes passenger with the help of a measure function that maps an individual and event to the numeral 1 just in case the event is a traveling event and the individual is an atomic person that is a participant in this event. In the case of nouns like grove, there is no event that the trees are participating that ensures they form a grove. There is merely spatiotemporal coincidence with the grove. What might be amenable to this style of analysis, though, is the verbal form of swarm. It could denote a plurality of moving events (having the spatiotemporal characteristics discussed in this section), each of which would be mapped to 1 by some measure given a participant of that event.
} 
predicates. In contrast, the analysis in (42) will ensure that swarm nouns, even those that have a plurality of members under $f$, denote atomic individuals with a spatial trace (defined in terms of the configuration of its constituent individuals), and will themselves be able to be in the extension of spatial stubbornly distributive predicates.

Having shown how the analysis of swarm nouns, as exemplified by (42), accounts for their defining properties, I want to return to that one point for which there is variation within the swarm nouns. In particular, the fact that some swarm nouns can behave like both plural count nouns and group nouns with respect to collective predicates and plural anaphora. Barker's 1992 proposal for group nouns is that they behave like plural denoting expressions with respect to constructions that can have access to their members via the membership function $f$. I proposed in the previous section that swarm nouns differ in that some, like swarm, denote individuals that are mapped to a plurality under $f$, while others, like grove, denote individuals that are mapped to themselves under $f$. I need to show now is that this difference does not prevent giving swarm nouns a unified analysis following (42). Suppose we are discussing a swarm of bees, then the meaning of swarm is given as in (43), where the only difference from (42) is the final predicate that requires the individuals that define the spatial partition to be bees.

$$
\begin{aligned}
\operatorname{swarm} \rightsquigarrow \lambda x \exists & \mathrm{P}[\operatorname{atom}(x) \wedge \varsigma(x)=\varsigma(f(x)) \wedge \\
& \text { partition }(\mathrm{P}, \varsigma(x)) \wedge \text { fine }_{\mu=\text { area }}(\mathrm{P}) \wedge \text { cluster }_{\infty}^{4}{ }_{\infty^{\text {prox }}}(\mathrm{P}) \wedge \\
& \forall s \in \mathrm{P} \exists y[\varsigma(y)=s \wedge \mathrm{BEE}(y)]]
\end{aligned}
$$

Besides their constituent individuals, the primary grammatical difference between a swarm and a grove is that $f$ will map the former to a plural individual, the sum of some bees, while $f$ will map the grove to itself. The only condition in (43) where this difference could matter is $\varsigma(x)=\varsigma(f(x))$, but it does not. Given that groves are mapped to themselves under $f$, this condition is immediately satisfied. In the case of a swarm, it merely requires that the sum of the members of the swarm as given by $f$ have the same spatial trace as the swarm individual. This is perfectly consistent with the rest of the formula in (43), which requires the existence of a fine, clustered partition of the spatial trace of the swarm individual, each member of which is the spatial trace of a bee. In fact, when a swarm individual $x$ is mapped to a plurality under $f$, the relevant partition will simply be the set of the spatial traces of its members, that is, the atomic parts of $f(x)$. The result is that we can account for differences within the class of swarm nouns, where only some are able to expose a plurality, while still giving all nouns with swarm reference a unified analysis. They will denote atomic individuals that are related to a plurality via a set of structural requirements placed on their spatial traces.

This section started with a series of new empirical arguments motivating a subclass of collective nouns that can be separated from canonical group nouns like committee. The rest of the section developed an analysis of these swarm nouns that is based on the idea that they denote individuals whose spatial trace has a particular structure to it. It must be divisible into a cluster of small parts, each of which is the spatial trace of an individual satisfying a lexically specified predicate. Example (44) summarizes the analysis for an arbitrary swarm noun, where PRED is some predicate determined by lexical and contextual factors. Additionally, individual lexical items might contribute additional conditions, as discussed above for bouquet, though (44) is meant to capture what they share. 


$$
\begin{aligned}
& \lambda x \exists \mathrm{P}\left[\operatorname{atom}(x) \wedge \varsigma(x)=\varsigma(f(x)) \wedge \operatorname{partition}(\mathrm{P}, \varsigma(x)) \wedge \text { fine }_{\mu=\text { area }}(\mathrm{P}) \wedge\right. \\
& \text { cluster } \left._{\infty \text { prox }}^{4}(\mathrm{P}) \wedge \forall s \in \mathrm{P} \exists y[\varsigma(y)=s \wedge \operatorname{PRED}(y)]\right]
\end{aligned}
$$

With this background in place, the next section argues that denotations like (44) are not the providence of nominals alone. In particular, I show that event-internal pluractional verbs have similar denotations, and that the peculiar properties of these verbs follow from the fact that they are predicates of swarms in the event domain.

\section{Event-internal Pluractionals: Swarms in the Event Domain}

It is best to first approach the notion of event-internal pluractionality through examples. Consider the case of Yurok, which has two pluractional morphemes that have been traditionally called the iterative and the repetitive (Garrett 2001). Examples (45-46) illustrate that the kinds of plural events they describe are very different.

\section{EVENT-INTERNAL \\ Ko'moy-o' ('o) prkwprkwr \\ hear-SG (LOC) REP.knock}

'I hear knocking.' (someone's at the door)

(Wood 2007: ex.7, p.148)

\section{kipun kwegeskwes-ek winter have.a.cold.ITR-1SG \\ 'I get colds in the winter.'}

(Wood 2007: ex.5c, p.146)

The repetitive in (45), which is our event-internal pluractional, describes a plurality of events that appear to cohere together as a single event, especially in contrast to the iterative in (46). For instance, an event of knocking at the door has repetitions as part of its character. That is, each knock is not independent, but part of a single event of requesting entry, which takes place on just one occasion. In contrast, the iterative in example (46) describes a plurality of events that cohere less. The colds happen on different occasions and they are clearly independent. They do not add up to an event with a singular character like the knocking event and the knocks that compose it. It is because the repetitions in examples like (45) appear to take place within an event that Cusic (1981: p. 67), building off of Dressler 1968, first calls them event-internal.

While the comparison between (45) and (46) is interesting in its own right, one of the major results in the pluractionality literature is the discovery that there is a crosslinguistically robust kind of pluractionality exemplified by (45) (Cusic 1981; Dressler 1968; Lasersohn 1995; Wood 2007; Xrakovskij 1997). In particular, based on a typological survey, Wood (2007: p. 87, ex. 45a) proposes a set of criteria that distinguish event-internal pluractionality from other kind of pluractionality. These criteria play an important role in this section, whose goals are twofold. First, I show that the Kaqchikel pluractional introduced in (3) is a prototypical event-internal pluractional in virtue of meeting these previously established criteria. I then show, through analyzing the Kaqchikel facts, that 
the properties of prototypical event-internal pluractional verbs follow immediately if they are the verbal equivalents of swarm nouns.

Before starting, it is important to note that the properties discussed below are not individually unique to event-internal pluractionals. While there pluractionals might cluster into various kinds based on sets of properties like those discussed below, there can be variation when considering particular pluractional morphemes. For instance, Bar-El 2008 discusses a pluractional morpheme in Skwxwú7mesh that is clearly not an event-internal pluractional (it is instead an event-external pluractional), but is opaque to distributivity like event-internal pluractionals tend to be. Similarly, Henderson 2012 discusses a second pluractional in Kaqchikel that does not belong to the event-internal category, but patterns similarly with respect to the cardinality restrictions discussed below. I will not be able to address these pluractional constructions or other types of pluractionality. The analysis is instead focused on accounting for the core properties of event-internal pluractionality discussed in Wood (2007: p. 87, ex. 45a), and thus prototypical event-internal pluractionals like $-\mathrm{Ca}$ ' in Kaqchikel.

\subsection{Kaqchikel -Ca' as an Event-internal Pluractional}

Before I show that event-internal pluractional verbs are the eventive counterparts of swarm nouns, I have to present the core data about a pluractional of this type. In particular, I will focus on the verbal derivation $-\mathrm{Ca}^{\prime}$ in Kaqchikel, illustrated by the following naturally occurring examples. ${ }^{21}$

\section{EVENT-INTERNAL}

a. Jun ak'wal yalan n-Ø-u-qeb'-eqa' r-i' pan ulew. a child much ICP-A3s-E3s-rub-Ca' E3s-REFL P earth

'A child is rubbing himself on the ground.'Chacach, Cali \& Cojtí 1999: p. 245

b. Jun xti moy r-onojel q'ij n-Ø-u-tzin-itza' ri ru-q'ojon pa a DIM blind E3s-all day ICP-A3s-E3s-strum-Ca' the E3s-guitar P k'ayb'äl. market

'A blind person strums his guitar all day in the market.' Chacach, Cali \& Cojtí 1999: p. 371

The rest of this section is devoted to showing that $\mathrm{Ca}$ '-marked predicates in Kaqchikel pattern with event-internal pluractionality crosslinguistically. In doing so, I simultaneously lay out the facts that the swarm-based analysis must capture.

The first generalization is that $-\mathrm{Ca}$ ' is sensitive to the aktionsart of the stem it modifies. Like event-internal pluractionals crosslinguistically Wood (2007: p. 87, ex. 45a), $-C a$ ' is felicitous with semelfactive stems, but not accomplishments. This is illustrated by the contrast between examples (48a-c) and (49a-c).

\footnotetext{
${ }^{21}$ You will have no doubt noted that in addition to the copied consonant, a vowel is also copied from the root in the examples above. It is only necessary for phonological reasons. For this reason, I will write the vowels in the Kaqchikel examples following the standardized orthography, but not segment or gloss them.
} 
a. X-Ø-u-chap-acha' ri ch'atäl. CP-A3s-E3s-touch-Ca' the table

'He kept tapping the table.'

b. X-Ø-u-k'oj-ok'a' ru-chi' ri jay.

CP-A3s-E3s-knock-Ca' E3s-mouth the house

'He kept knocking at the door.'

c. X-Ø-u-t'in-it'a' ri kem.

CP-A3s-E3s-hammer(weft)-Ca' the weaving

'He kept hammering the weft of the weaving.'

\section{ACCOMPLISHMENTS}

a. \#X-Ø-u-b'an-ab'a' ri jay.

CP-A3s-E3s-build-Ca' the house

'He kept building the house.'

b. \#X-Ø-u-tz'ib'a-tz'a' ru-b'i.

CP-A3s-E3s-wrote-Ca' E3s-name

'He kept writing his name.'

c. \#X-Ø-u-kem-eka' ri po't.

CP-A3s-E3s-weave-Ca' the blouse

'He kept weaving the blouse.'

It is natural to think of semelfactives and accomplishments as polar opposites. Intuitively, accomplishments are temporally extended events that involve incremental progress toward a result state. Semelfactives are punctual events that entail no result state. In between these two extremes, we have achievements and activities. The former are not temporally extended, but they are like accomplishments in having a result state. The latter are like accomplishments in being temporally extended, but have no result state. The interaction of achievements and activities with $-\mathrm{Ca}$ ' shows them to be somewhere between accomplishments and semelfactives. While these stems do not completely reject derivation by $-\mathrm{Ca}$, they are felicitous insomuch as they can have a semelfactive-like reading under aspectual coercion.

Let's start with achievements. An achievement is grammatical with $-\mathrm{Ca}$ ' only if it can be treated as denoting events that fail to culminate as they usually do. This is illustrated in (50a-c), especially through the speaker comments. 
a. X-Ø-in-ch'ar-ach'a' ri tros. CP-A3s-E3s-split-Ca' the stump

'I kept chopping at the stump.'

SPEAKER COMMENT: It's like if your axe is really dull.

b. X-Ø-in-tzuy-utza'. CP-A3s-E3s-sit-Ca'

'I kept (making the motion of) sitting there.'

SPEAKER COMMENT: Your bottom doesn't really hit the chair.

c. X-Ø-u-yuch'-uya' ri su't.

$\mathrm{CP}-\mathrm{A} 3 \mathrm{~s}-\mathrm{E} 3 \mathrm{~s}-$ double.over-Ca' the wrap

'I kept folding over the wrap.'

SPEAKER COMMENT: Like if you can't get it lined up even.

This aspectual coercion is not just pragmatic, but has detectable semantic effects. If $\mathrm{Ca}$ 'marked predicates denote events which must not culminate, it is predicted that a sentence with a coerced achievement should not entail a minimally different non-pluractional sentence. The reason is that, after coercion, the truth of the pluractional sentence will not ensure the existence of an event that satisfies its non-pluractional counterpart. This prediction is borne out in (51-52). Note that we have the same verb stem across the positive and negative clauses in the following examples. The difference in meaning is attributable to the pluractional derivation.
$X$ - $\varnothing$-in-ch'ar-ach'a' ri tros, po man $x$ - $\emptyset$-ch'ar ta. CP-A3s-E1s-split-Ca' the stump, but NEG CP-A3s-split.PAS IRR

'I kept chopping at the stump, but it didn't split.'

\section{$X-\emptyset$-u-tzuy'-utza', po man $x$-Ø $\varnothing$-tzuy-e' ta. CP-A3s-E3s-sit-Ca', but NEG CP-A3s-sit IRR}

'She kept sitting up and down there, but she didn't sit.'

As a control, note that the entailment goes through with $\mathrm{Ca}^{\prime}$ '-marked semelfactives. This is because each of the repeated events that the pluractional requires will satisfy the nonpluractional predicate.

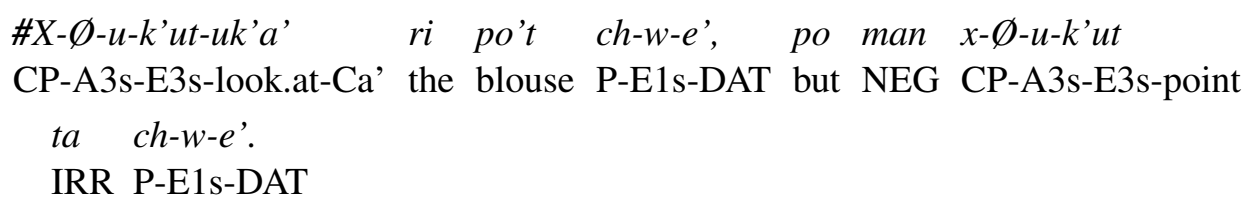

'She kept showing me the blouse, but she didn't show it to me.' 
(54)
\#X-Ø-u-pitz'-ipa'
ri pix
po man $x$-Ø-u-pitz'
ta. CP-A3s-E3s-squeeze-Ca' the tomato, but NEG CP-A3s-E3s-squeeze IRR

'She kept squeezing the tomato, but she didn't squeeze it.'

The case of activities is similar. An activity cannot be derived by $-\mathrm{Ca}$ ' without greatly altering the character of the events that the stem usually denotes. Activities have no result state, making them like semelfactives in this way, but they are temporally extended. Activities are felicitous with $-\mathrm{Ca}^{\prime}$ if it is possible to construe the verb stem as denoting non-temporally extended events. The comparison between the (a) and (b) examples below shows that the pluractional derivation prevents the activity from progressing.

a. X-Ø-u-chok-ocha' ri ch'ich'.

CP-A3s-E3s-push-Ca' the car

'He kept pushing on the car.'

SPEAKER COMMENT: It's like it's stuck and keeps rocking back into place.

b. Oxi' hora $x$ - $\emptyset$-u-chok-omij pe ri ch'ich'.

three hours CP-A3s-E3s-push-VTD DIR the car.

'He pushed the car here for three hours.'

a. X-Ø-u-sir-isa' ri koloch'.

CP-A3s-E3s-roll-Ca' the ball

'I kept rolling the ball (back and forth in place).'

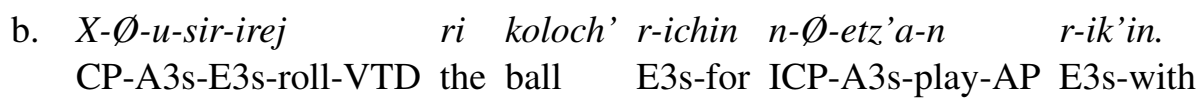

'He rolled the ball to play with it.'

(57) a. X-i-ru-tz'et-etz'a'.

CP-A1s-E3s-look.at-Ca'

'He kept glancing at me.'

b. Jun hora $x$-i-ru-tz'et.

one hour CP-A1s-E3s-look.at

'He looked at me for an hour.'

Another way to characterize the effect of the pluractional is that it requires the repetition of some initial subpart of an event that would satisfy a similar non-pluractional predicate. Once again, the type of coercion observed makes these stems approximate a semelfactive. The repeated events are not normal activities, but events that cannot be temporally extended. 
Summarizing, $-\mathrm{Ca}$ ' is sensitive to the aktionsart of the stem to which is applies. It is well-attested for event-internal pluractionals to preferentially target semelfactives (Wood 2007: p. 89). This is precisely what we see with $-\mathrm{Ca}$ '. It is grammatical with semelfactives, ungrammatical with accomplishments, and acceptable with achievements and activities insomuch as they can be coerced into predicates of events that are short and do not culminate - that is, events with a semelfactive profile. Plausibly, the reason why accomplishments like (49a-c) cannot be successfully coerced is that even if their end states are removed, they have complex, heterogeneous preparatory processes, which cannot be easily reduced to a single, punctual, repeatable event. A core goal for the analysis developed in the following section is to show that the preference for semelfactive verbs, and the need for semelfactive coercion in other cases, is a consequence of the fact that event-internal pluractionality is swarm reference in the event domain.

The second way that $\mathrm{Ca}$ '-marked predicates pattern with event-internal pluractional verbs crosslinguistically is that the parts of the plural events they denote are nearly contiguous (Wood 2007: p. 90). The following examples illustrate this point in a controlled manner, but even the naturally occurring examples in (47a-47b) and (3) describe scenarios that could only involve contiguous repetitions.

(58) Suppose Juan knocks on the door once every 10 seconds for 10 minutes.

\#A Xwan $x$ - $\emptyset$-u-k'oj-ok'a' ru-chi' ri jay.

CLF Juan CP-A3s-E3s-knock-Ca' E3s-mouth the door

'Juan kept knocking at the door.'

SPEAKER COMMENT: No, it has to be continuous.

(59) Suppose Juan has a rash on his arm and every so often it itches so he scratches it.

\#A Xwan $x$-Ø-u-roch-ora' r-aq'a.

CLF Juan CP-A3s-E3s-scratch-Ca' E3s-hand

'Juan kept scratching his arm.'

SPEAKER COMMENT: No, it would be like this: [scratches vigorously back and forth on her arm].

(60) Suppose you see Juan every day and he gives you a dirty look.

\#A Xwan x-i-ru-tz'et-etz'a'.

CLF Juan CP-A1s-E3s-look.at-Ca'

'Juan keeps looking at me.'

SPEAKER COMMENT: No, it would have to be like this: [speaker turns his head a bit and shoots a glance over and over].

The scenarios in (58-60) look at downtimes ranging from 10 seconds to days. Crucially, $-\mathrm{Ca}$ ' cannot be used. Speakers' comments make this clear, especially when they act out scenarios in which $-\mathrm{Ca}^{\prime}$ would be appropriate. They always use rapid, almost frantic, contiguous repetitions, which is expected from an event-internal pluractional. 
Another distinguishing property of event-internal pluractionals, which is especially interesting if we want to assimilate them to a species of nominal plurality, is that the events they denote must have a large, though contextually specified cardinality (Wood 2007: p. 79). Examples (61-63) show that $\mathrm{Ca}^{\prime}$-marked predicates have this property. They require many repetitions.

(61) Suppose Juan looks over at you twice.

\#A Xwan x-i-ru-tz'et-etz'a'.

CLF Juan CP-A1s-E3s-look.at-Ca'

'Juan keeps looking at me.'

(62) Suppose Juan taps the table 4 or 5 times.

\#A Xwan $x$-Ø-u-chap-acha' ri ch'atäl.

CLF Juan CP-A3s-E3s-touch-Ca' the table

'Juan keeps touching the table.'

(63) Suppose Juan taps the table 15 or 20 times.

A Xwan $x$-Ø-u-chap-acha' ri ch'atäl.

CLF Juan CP-A3s-E3s-touch-Ca' the table

'Juan keeps touching the table.'

Another argument for this position is that $-\mathrm{Ca}$ ' often occurs with high intensity adverbials in naturally occurring examples. For instance, the sentences in (47) contain adverbials like yalan 'very/a lot' and ronojel q'ij 'all day'. These adverbials can be treated as further fixing the contextually specified cardinality of repetitions. The fact that they uniformly indicate large numbers of repetitions supports the data in (61-63).

Finally, $\mathrm{Ca}$ '-marked predicates behave like event-internal pluractionals when interacting with distributivity. In particular, the parts of the plural event that satisfy the pluractional predicate are completely opaque to all flavors of distributivity. Because it is not possible to distribute the parts of one of these events over individuals, the result is that arguments of $\mathrm{Ca}^{\prime}$-marked predicates must participate in plural events under both distributive predication and distributive quantification. For instance, example (64) has no reading where each of the individuals in the extension of the plural subject participates in a single glancing event, even if the sum of those events has the appropriate cardinality and temporal profile. Instead, the only reading of (64) has each of the people repeatedly glancing at me.

(64) Suppose there is a large group of people across the street and they each turn and glance at me once.

\#X-i-ki-tz'et-etz'a' ri winaq-i'.

CP-A1s-E3p-look.at-Ca' the person-PL

'The people kept glancing at me.' 
(65) Suppose a bunch of people come by my market and pick up a particular tomato, squeeze it once, and put it down.

\#X-Ø-ki-pitz'-ipa' la jun xkoya' la'.

CP-A3s-E3p-squeeze-Ca' that one tomato there

'They kept squeezing that tomato.'

Not surprisingly, appending a distributive quantifier like chikijujunal 'each of them' does not generate the target interpretation. For instance, examples (66-67) cannot have a reading where each individual in the extension of the plural subject participates in a single event. They must all participate in plural events.

(66) Suppose there is a large group of people across the street and they each turn and glance at me once.

\#Chi-ki-ju-jun-al ri winaq-i' $x$-i-ki-tz'et-etz'a'.

P-E3p-one-RED-NOM the person-PL CP-A1s-E3p-look.at-Ca'

'Each of the people kept glancing at me.'

(67) Suppose a bunch of people come by my market and pick up a particular tomato, squeeze it once, and put it down.

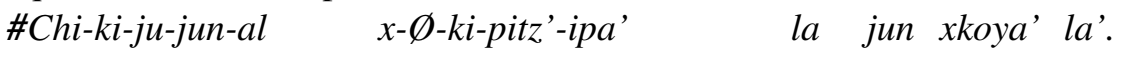

P-E3p-one-RED-NOM CP-A3s-E3p-squeeze-Ca' that one tomato there

'They each kept squeezing that tomato.'

All that the distributive quantifier does is rule out collective interpretations of pluractional predicates, which are otherwise licit.

(68) Suppose a group of people are trying to push a big bus, but are having trouble moving. It just keeps rocking back and forth.

$X$-Ø-ki-chok-ocha' ri ch'ich'.

CP-A3s-E3p-push-Ca' the bus

'They kept pushing on the bus.'

(69) Suppose a group of people are trying to push a big bus, but it is having trouble moving. It just keeps rocking back and forth.

\#Chi-ki-ju-jun-al x-Ø-ki-chok-ocha' ri ch'ich'.

P-E3p-one-RED-NOM CP-A3s-E3p-push-Ca' the bus

'Each of them kept pushing on the bus.'

By resisting distribution over pluractional subevents, the suffix $-\mathrm{Ca}$ ' behaves exactly as we would expect if it derived event-internal pluractional predicates. The swarm-based analysis developed in the following section is able to explain in a unified way, both the observed opacity to distributivity, as well as the aspectual and temporal generalizations presented above. 


\subsection{A Swarm-based Account of Event-internal Pluractionality}

$\$ 2$ argued that swarm nouns have a particular kind of collective reference mediated by an individual's spatial trace. For instance, a grove is an atomic individual whose spatial trace can be divided into a cluster of very small parts, each of which is the spatial trace of a individual satisfying a lexically given predicate, namely tree. I propose that $-\mathrm{Ca}$ ' derives predicates with the same type of group reference in the event domain. In particular, (70) gives the denotation of $-\mathrm{Ca}$, which has the same core features of the schematic denotation for swarm nouns in (44). ${ }^{22}$ Note that the particular cluster predicate lexically specified by $-\mathrm{Ca}$ ' uses adjacency, which is defended below. This actually mandates that the numeral parameter be 1 . The reason is that times are linearly ordered, and so the first and last temporal trace in the partition could only be strictly adjacent to one other temporal trace in the partition.

$$
\begin{gathered}
-\mathrm{Ca}^{\prime} \rightsquigarrow \lambda V_{\varepsilon t} \lambda e \exists \mathrm{P}\left[\operatorname{atom}(e) \wedge \operatorname{partition}(\mathrm{P}, \tau(e)) \wedge \text { fine }_{\mu=l e n g t h}(\mathrm{P}) \wedge \text { cluster }_{\infty}^{1}(\mathrm{P}) \wedge\right. \\
\left.\forall t \in \mathrm{P} \exists e^{\prime}\left[\tau\left(e^{\prime}\right)=t \wedge V\left(e^{\prime}\right) \wedge e[\tau] e^{\prime}\right]\right], \text { where: }
\end{gathered}
$$

a. $e[\tau] e^{\prime}$ means $e$ and $e^{\prime}$ differ at most with respect to their temporal trace. That is, it is shorthand for $\forall \mathrm{T}\left(\mathrm{T}(e)=\mathrm{T}\left(e^{\prime}\right)\right)$, where $\mathrm{T}$ ranges over all trace functions and thematic roles, excluding $\tau$.

Most importantly, (70) is similar to (44) in that, after composing with a verb stem, it is a predicate of atoms that have a trace which is divisible into very small parts, each of which is the trace of another entity that satisfies a second predicate. ${ }^{23}$ This ensures that any event that satisfies a $\mathrm{Ca}^{\prime}$-marked predicate must have swarm reference.

While $C a^{\prime}$-marked verbs are swarm-denoting, there are a few differences between (70) and the schematic denotation of swarm nouns in (44). Crucially, though, none of them reflect deep differences between swarm nouns and event-internal pluractional verbs. They instead reflect accidental properties of the pluractional at hand, or ontological differences between individuals and events that go beyond the analysis of swarm-based collective reference.

First, note that there is a type-difference between (70) and (44). Each event that constitutes the swarm must satisfy a predicate that is not lexically given, but provided compositionally by the verb stem that the pluractional affixes. $\$ 4$ shows, though, that this is an accidental fact which cuts across both the nominal and verbal domains. There are languages with nominal derivations that derive swarm nouns from a wide variety of nominal stems, like the pluractional. Similarly, example (70) is different from (44) in that

\footnotetext{
${ }^{22}$ Since $-\mathrm{Ca}$ ' makes use of a temporal trace, not a spatial trace, the $\mu$ employed in (70) measures the length of the interval.

${ }^{23}$ Instead of putting atomic events in the model, another option would be to assume that $-\mathrm{Ca}$ ' derives predicates of events that are taken to be indivisible relative to the context and the description at hand, as in Rothstein 2010. That is, if we abbreviate the formula after the lambdas in (70) as EI-plrc (even-internal pluractional), a two place relation between events and predicates of events, then $-\mathrm{Ca}$ ' could be translated as $\lambda V_{\epsilon t} \lambda e[\mathbf{E I}-\operatorname{plrc}(e, V) \wedge \operatorname{MEAS}(e)=<1, U>]$, where $U$ is a contextually supplied variable containing the set of events that count as 1 in the context. A $\mathrm{Ca}$ '-marked verb would then denote a set of pluractional events that are additionally treated as minimal elements for the purposes of the context - that is, with respect to a $U$-relativized part-whole relation $\leq_{\epsilon}^{U}$.
} 
the swarm event is defined in terms of the temporal trace function, but there are eventinternal pluractionals in other languages that make use of the event argument's spatial trace (Collins 2001; Wood 2007: p.64-70), smoothing out this apparent difference. ${ }^{24}$

The third difference is the absence of an eventive version of the condition $\varsigma(x)=$ $\varsigma(f(x))$. In the individual domain, this condition ensured that when swarm was related to a plurality via the membership function, that plurality had to have the same spatial trace as the swarm. This was to rule out the aberrant situation where a swarm was an atomic individual whose spatial trace could partitioned into many small parts, each of which was the trace of a bee, but its members were some totally different plurality of bees. This condition is not necessary in the event domain because there is currently no evidence that we need to have a membership function for events parallel to what we have in the individual domain. If this were the case, we would expect to have a class of verbs that denoted events with the same character as canonical group individuals like committees. In the absence of these kinds of verbs, this condition can be safely removed. ${ }^{25}$ The fact that there might not be an verbal analog of canonical group nouns is perhaps not surprising. Membership is meant to capture a variety of abstract relationships between individuals and the groups they constitute, which seem to not be operative in the domain of events, which are usually individuated in terms of the their spatial / temporal traces and participants. For instance, it is hard to imagine a class of events, like committees, that would remain identical under the addition or substitution of constituent events.

The last difference between the analysis of event-internal pluractionality and the analysis of swarm nouns concerns the final condition in (70). While it is true that I do not make use of trace equivalence in (44) - e.g., $e[\tau] e^{\prime}$, the point is moot. Individuals only have a spatial trace, and so adding a trace equivalence condition to (44) does no work. The larger point is that events and individuals are ontologically different, the former being individuated in terms of various trace functions, and so we do not expect expressions that make reference to swarms across domains to have the same exact representations. Instead, what is carried over from (44) to (70) are precisely those features that establish swarm reference, namely those conditions that superimpose an atomic entity on a plurality by means of a trace function. It is these conditions that explain the core properties of event-internal pluractionality that we have encountered.

I now want to show that the swarm-based analysis in (70) accounts for all of the properties of event-internal pluractionality. Recall the first three generalizations about $\mathrm{Ca}$ '-marked predicates. To begin, they only compose with semelfactive verb stems apart from coercion. Activities, achievements, and accomplishments are only acceptable if they can be coerced into a semelfactive. Second, these repetitions must be contiguous and

\footnotetext{
${ }^{24}$ For instance, Collins 2001 describes a pluractional in $\neq$ Hoan, illustrated in (71), that derives verbs which can only be satisfied by a plurality of events taking place in a variety of locations.

(71) a. ciu 'dig' $\rightarrow$ kí'-ciu-qllo 'dig around'

b. 'am 'eat' $\rightarrow$ kí'-'am-q\|lo 'eat around'

${ }^{25}$ Note that discovering such a class of verbs would not disrupt the analysis. We would merely have to add back in the condition $\varsigma(x)=\varsigma(f(e))$, which would once again be trivially satisfied for those swarm verbs denoting events that are mapped to themselves under $f$, just as with swarm nouns like grove or bouquet.
} 
take place on a single occasion. Finally, the number of repetitions is large and fixed by context. The analysis I propose draws these three generalizations together. All will have

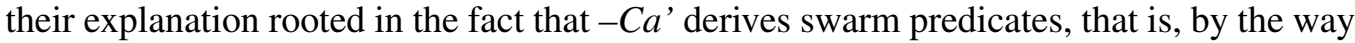
it relates an atomic event to a plurality by means of a trace function.

Consider a concrete example like (72), repeated from (59). Its truth conditions are given in (73). The first two lines are the result of applying (70) to the event predicate roch 'scratch'. The last line relates the pluractional event to its arguments via theta roles. ${ }^{26}$

(72) Suppose Juan has a rash on his arm and every so often it itches so he scratches it. \#A Xwan $x$ - $\emptyset$-u-roch-ora' $\quad r$ - $a q^{\prime} a$. CLF Juan CP-A3s-E3s-scratch-Ca' E3s-hand

'Juan kept scratching his arm.'

SPEAKER COMMENT: No, it would be like this: [scratches vigorously back and forth on her arm].

$$
\begin{aligned}
& \exists e \exists \mathrm{P}\left[\operatorname{atom}(e) \wedge \text { partition }(\mathrm{P}, \tau(e)) \wedge \text { fine }_{\mu=\text { length }}(\mathrm{P}) \wedge \text { cluster }_{\infty}^{1}(\mathrm{P}) \wedge\right. \\
& \left.\forall t \in \mathrm{P} \exists e^{\prime}\left[\tau\left(e^{\prime}\right)=t \wedge \operatorname{SCRATCH}\left(e^{\prime}\right) \wedge e[\tau] e^{\prime}\right]\right] \\
& \wedge \mathbf{a g}(e)=J \wedge \operatorname{th}(e)=x \wedge \operatorname{ARM}(x) \wedge R(J, x)]
\end{aligned}
$$

The formula in (73) is true if there is an atomic event $e$ whose temporal trace can be partitioned into many very short adjacent intervals that are traces of scratching events. Each of those events has to have John as its agent and an arm as it patient, which must stand in the appropriate relationship to John (e.g., inalienable possession).

First of all, the analysis immediately explains why (72) is only true in scenarios that have John scratching his arm a large number of times. The explanation is parallel to how the analysis accounts for the fact that a grove must consist of a large number of trees. Because $P$ in (73) must be a fine partition of the pluractional event's temporal trace, we know that $P$ must have many members. But each of those members must be the temporal trace of a scratching event, which means that (73) entails a large number of repeated scratchings. Moreover, the particular number of repetitions is predicted to be context dependent. The reason is that $\mathrm{P}$ is defined as a set of temporal intervals, each of which is very short relative to $\tau(e)$, and this is a gradable, and thus contextually dependent notion.

The analysis further accounts for the fact that the repetitions should be contiguous. This immediately follows from the particular instantiation of the cluster predicate lexically specified by the pluractional derivation. For $\operatorname{cluster}_{\infty}^{1}(\mathrm{P})$ to hold, each time in $\mathrm{P}$ must be strictly adjacent to at least one other time in $\mathrm{P}$. The result is a set of contiguous temporal traces. The analysis thus accounts for the infelicity of (72) in the offered context. There can be no downtime between the scratching events. As a corollary, the analysis makes sense of one of the core differences between event-internal pluractionality and other kind of pluractionality, namely that the latter can be satisfied by a plurality of events that take place on different occasions (see 45-46 and surrounding discussion). The reason is that

\footnotetext{
${ }^{26}$ Note that for reasons of space, I do not show how verbs compose with their arguments. Providing a compositional analysis is ancillary to the main goals of the analysis, and to do so would not be difficult given that the pluractional is merely a verb modifier of type $\langle\varepsilon t, \varepsilon t\rangle$.
} 
occasional readings, like that exemplified in (46), permit downtime between the events that constitute the pluractional event.

The combination of the previous two points - the need for short, and thus many events, and the fact that the repetitions are contiguous-provides an explanation for the fact that $-\mathrm{Ca}$ ' targets only semelfactives apart from coercion. First, consider the case of activities. We have seen that $C a^{\prime}$-marked activities are only satisfied by repetitions of a short initial segment of an event that the relevant activity verb would usually denote. This is immediately predicted by the definition of swarm reference. By the definition of a fine partition, each of the events composing the swarm must have a very short temporal trace, much shorter than the trace of the pluractional event as a whole. Furthermore, each must satisfy the verb stem $-\mathrm{Ca}$ ' suffixes. If the verb stem is semelfactive, these conditions can be immediately met. Semelfactive events are already short, and so they can surely fall in the extension of a semelfactive stem that $-\mathrm{Ca}$ ' suffixes. If the stem is an activity, though, which naturally denotes events that are temporally extended, coercion takes place. The pluractional event will have to be composed of a large number of very short events that fall in the extension of the activity stem. If it is possible to find such events, even abnormal ones, the expression will be felicitous. This is exactly what we find in examples like (55-57).

The kind of coercion observed with achievements has a different explanation than that which we see with activities. In particular, I attribute it to the contiguity condition on swarms. Recall that achievements are only grammatical with $-\mathrm{Ca}$ ' if they can be construed as denoting events that do not culminate. The analysis I propose follows from an idea of Rothstein 2004 (rooted in early work by Kamp 1979), which is that semelfactive events, in virtue of entailing no significant result state, are inherently repeatable. This is because the occurrence of the event cannot have an effect that interferes with the prerequisites of a similar event immediately occurring again. That is, when I give the door a single knock, nothing happens to my hand or the door that precludes immediately appending another knocking event. The same is true for events in the extension of predicates like rop 'flap', roch 'scratch', chäp 'touch', pïtz' 'squeeze', etc., which are all readily affixed by $-C a$ ' in Kaqchikel.

In contrast, the normal course of an achievement event entails that an end state must hold, precluding the immediate repetition of the same event. For example, a sitting event usually ends with the subject having the property of being seated for some appreciable amount of time. During that time, that individual is clearly not sitting again. The same is true for $y u c h$ ' 'double over' or ch'ar 'split'. Once an object is split or doubled over, to repeat the same event, it must be undoubled or unsplit. The idea, then, is that the pluractional, in virtue of requiring contiguous repetitions, requires the downtime between events in the swarm to be minimal. This means that the result state entailed by achievements must be minimized. This is precisely what we see with examples like (50a-c). For instance, the pluractional expression in (50b), which is built on the stem tzuy 'sit', requires repetitions of sitting events where the subject does not get seated. This makes sense if each sitting event in the swarm must be contiguous with another sitting event; all of the time spent seated will be time separating the previous sitting event from the next one, interfering with the satisfaction of the contiguity condition. By coercing the achievements so that their result states are minimized, they become like semelfactives, which are inherently 
repeatable in a contiguous manner.

The swarm-based analysis of $-\mathrm{Ca}$ ' clearly captures the temporal and aspectual properties of event-internal pluractionality, both in Kaqchikel and more generally. It also makes a series of correct predictions about the interaction of distributive operators and pluractional predicates.

First, though, recall examples (64-67), which show that the pluractional is opaque to both predicative and quantificational distributivity. The analysis correctly predicts the inability to pair atomic individuals with non-pluractional events under various flavors of distributivity. I start with quantificational distributivity. Example (74) shows that chikijujunal 'each' forces distributive readings of so-called mixed predicates. Formula (75) captures the truth conditions of (74) if chikijujunal is translated by a universal quantifier that scopes over the event quantifier. In particular, (75) requires each of the women to participate in their own event of lifting Irma.

$$
\begin{array}{lllllll}
\text { Chikijujunal } & r i & \text { ixoq- } i & x-\emptyset-k i-j o t-o b ' a & r i & x t a & \text { Irma. } \\
\text { Each } & \text { the woman-PL } & \text { CP-A3s-E3p-elevated-SS } & \text { the CLF } & \text { Irma }
\end{array}
$$

'The women each lifted Irma.'

FALSE if there was a collective lifting event

$$
\forall x[\operatorname{woman}(x) \rightarrow \exists e[\operatorname{LiFT}(e) \wedge \mathbf{t h}(e)=I \wedge \mathbf{a g}(e)=x]]
$$

When we move to an event-internal pluractional example like (66), each individual must be paired with a pluractional event, exactly as required. Its truth conditions are given in (76), where Sp is a distinguished variable that picks out the speaker in a context.

$$
\begin{aligned}
& \forall x\left[\operatorname { P E R S O N } ( x ) \rightarrow \exists e \exists \mathrm { P } \left[\operatorname{atom}(e) \wedge \operatorname{partition}(\mathrm{P}, \tau(e)) \wedge \text { fine }_{\mu=\text { length }}(\mathrm{P}) \wedge\right.\right. \\
& \text { cluster } \left._{\infty}^{1}(\mathrm{P}) \wedge \forall t \in \mathrm{P} \exists e^{\prime}\left[\tau\left(e^{\prime}\right)=t \wedge \operatorname{LOOK} \cdot \mathrm{AT}\left(e^{\prime}\right) \wedge e[\tau] e^{\prime}\right]\right] \wedge \\
& \text { th }(e)=\mathrm{Sp} \wedge \mathbf{a g}(e)=x)]
\end{aligned}
$$

We have the same result when turning to distributive predication. There are a variety of recent event-based approaches to distributivity (e.g., Brasoveanu \& Henderson 2009; Champollion 2010; Lasersohn 1998 among others). They will all make the correct predictions about the truth conditions of a sentence with an event-internal pluractional predicate and a distributively interpreted argument—in particular, such a sentence will be true just case in each member of the plural argument participates in their own pluractional event. To see this, consider the account in Brasoveanu \& Henderson 2009. First, they assume that verbs denote cumulatively closed predicates of events. Cumulative closure, also called algebraic closure, is defined following Link 1983/2002.

(77) Cumulative Closure.

The cumulative closure of $P$ is the smallest predicate $* P$ such that:

a. $P \subseteq * P$

b. if $a \in * P$ and $b \in * P$, then $a \oplus b \in * P$ 
Against this backdrop, non-quantificational distributivity, like predicative distributivity, is analyzed in Brasoveanu \& Henderson 2009 based on what they call functionally encapsulated distributive dependencies. In particular, distributive dependencies are encoded in the way a theta-role function maps events to individuals. In particular, the minimal subparts of an event are mapped to the minimal subparts of that event's thematic argument. For instance, the schematic example (78) would be translated as in (79).

The $\mathrm{P}$ dist-V.

$$
\exists e\left[* \mathrm{~V}(e) \wedge \mathbf{a g}(e)=\sigma x{ }^{*} \mathrm{P}(x) \wedge \forall e^{\prime} \leq e\left[\operatorname{atom}\left(\mathbf{e}^{\prime}\right) \rightarrow \operatorname{atom}\left(\operatorname{ag}\left(\mathbf{e}^{\prime}\right)\right)\right]\right]
$$

The formula in (79) says that 'The $\mathrm{P}$ (dist) $\mathrm{V}$ ' is true just in case there is an event $e$ that satisfies $* \mathrm{~V}$, the agent of $e$ is the sum of all P-individuals, and each atomic part of $e$ has an atomic agent. By structuring the way the theta-role maps events to individual, formula (79) rules out situations in which there is a V-event with a plural participant.

If we take pluractional verbs, like verbs in general, to be cumulatively closed, the result for -tz'et-etz' $a$ ' in (80), repeated from (64), is given in (81). It is important to note that the $*$-marked predicate of events in $(81)$ is just the normal meaning that has been given to the Kaqchikel pluractional verbs.

$$
\begin{array}{ll}
X-i-k i-t z ' e t-e t z '{ }^{\prime} & \text { ri winaq-i'. } \\
\text { CP-A1s-E3p-look.at-Ca' the person-PL }
\end{array}
$$

'The people kept glancing at me.'

$$
\begin{aligned}
& \text {-tz'etetz'a } \rightsquigarrow \lambda e^{\prime}\left[e^{\prime} \in * \lambda e . \exists \mathrm{P}\left[\operatorname{atom}(e) \wedge \operatorname{partition}(\mathrm{P}, \tau(e)) \wedge \text { fine }_{\mu=l e n g t h}(\mathrm{P}) \wedge\right.\right. \\
& \text { cluster } \left._{\infty}^{1}(\mathrm{P}) \wedge \forall t \in \mathrm{P} \exists e^{\prime}\left[\tau\left(e^{\prime}\right)=t \wedge \operatorname{LOOK} . \operatorname{AT}\left(e^{\prime}\right) \wedge e[\tau] e^{\prime}\right]\right]
\end{aligned}
$$

It is clear that (81), in virtue of the $*$-operator, is a predicate of atomic swarm events as well as sums of atomic swarm events. To keep denotations readable, I will abbreviate the cumulatively closed predicate of events in (81) as *look.plrc. Plugging this cumulatively closed predicate of events into a formula like (79), we get the following truth conditions for $(80)$.

$$
\begin{aligned}
& \exists e\left[* \operatorname{look} \cdot \operatorname{plrc}(e) \wedge \mathbf{a g}(e)=\sigma x . * \operatorname{PERSON}(x) \wedge \forall e^{\prime} \leq e\left[\operatorname{atom}\left(\mathbf{e}^{\prime}\right) \rightarrow \operatorname{atom}\left(\operatorname{ag}\left(\mathbf{e}^{\prime}\right)\right)\right]\right. \\
& \wedge \mathbf{t h}(e)=\mathbf{S p}]
\end{aligned}
$$

The formula in (82) has two critical pieces as far as distributive readings are concerned: (i) there must be an event $e$ that is the sum of some number of swarm events, namely those that satisfy the *-marked predicate in (81), and (ii) each atomic part of $e$ has to have an atomic agent. The result is that each person must be the agent of at least one (atomic) event that satisfies the pluractional (swarm) predicate, which is precisely the truth conditions speakers report for (80). Each person has to participate in their own pluractional event of shooting me many quickly repeated glances. It is not true if each person merely looks at me once in quick succession. This shows that giving event-internal 
pluractional verbs a swarm-based analysis can account for the attested readings under predicative distributivity, as well as quantification distributivity.

In sum, this section has argued for two interrelated claims. First, I have demonstrated that the Kaqchikel derivation $-\mathrm{Ca}$ ' is a canonical example of event-internal pluractionality. Second, I have shown that the properties of $\mathrm{Ca}$ '-marked predicates in Kaqchikel follow immediately if the pluractional derives predicates with swarm reference in the event domain. Most importantly, the analysis treats event-internal pluractional verbs in Kaqchikel as the verbal counterparts to the swarm nouns discussed in $\S 2$. This means that natural language reuses even fine-grained subtypes of plural reference across the individual and event domains. Finally, because the Kaqchikel pluractional exemplifies a common type of pluractionality attested crosslinguistically, the analysis is expected to extend to other languages. The fact that we can reduce a typologically common form of pluractionality to a species of collective reference that is identifiable in the nominal domain is a satisfying conclusion. The rest of the paper extends this result. In particular, the final section argues that there are languages with nominal derivations that generate swarm nouns. This means that not only are there languages that clearly grammaticalize swarm reference in the nominal domain, but their compositional semantics makes the parallels with event-internal pluractionality even clearer.

\section{Deriving Swarm Nouns Compositionally}

There is one small difference between the analysis of swarm nouns and event-internal pluractional verbs that has not yet been touched on. Digging deeper, though, we find that this surface difference is a further argument for the crosslinguistic similarity of these two classes of expressions. In particular, the swarm nouns presented thus far are lexical predicates, while event-internal pluractional verbs are morphologically derived. If there were complete morphosemantic unification between these two classes of expressions, there should be morphemes that derive swarm nouns out of arbitrary predicates. That is, just like pluractional affixes, the relevant morpheme should take a nominal predicate $P$ and derive a predicate of atoms whose spatiotemporal trace is covered by $P$ individuals. While there do not appear to be any such nominal derivational morphemes that are as widely productive as the pluractionals, we do find the productive marking of swarm nouns within certain lexical domains. For instance, Romanian has the suffixes -et and $-i$ ş, deriving swarm nouns from nouns denoting species of trees (Chelaru-Ionita \& Bantas 1978). ${ }^{27}$
a. brad 'fir tree'
b. brăd-et 'fir-tree grove/forest'
c. fag 'beech tree'
d. fãg-et 'beech grove'

\footnotetext{
${ }^{27}$ These suffixes are found throughout the Romance languages, often related to the Latin suffix -etum, which productively derives nouns referring to assemblages of trees (e.g., robor-etum 'oak wood', salic-etum 'willow grove') (Carnoy 1917: p. 187).
} 

a. carpen 'hornbeam tree'
b. cărpin-iş 'hornbeam forest'
c. alun 'hazel tree'
d. alun-iş 'hazel tree grove'

While these Romanian suffixes have a restricted distribution, they are productive within that domain, and so it is part of a speaker's grammatical knowledge that when an expression carries one, it has swarm reference. ${ }^{28}$ This is clear from the fact that these nouns pass all of the tests that their monomorphemic English counterparts do.

First, Romanian derived swarm nouns, unlike simple plural count nouns, are ungrammatical with collective predicates. In this way they pattern with underived swarm nouns like grove, which do not expose a plurality.

a. *Alun-iş-ul acela arată bine împreună. hazel-group-DEF that look well together

'That hazel grove looks good together.'

b. Aluni-i aceia arata bine împreună. hazel-PL those look well together

'Those hazel trees look good together.'

a. *Alun-iş-ul acela seamana unul cu altul. hazel-group-DEF that resemble one with other

'That hazel grove resembles one another.'

b. Aluni-i aceia seamana unul cu altul. hazel-PL those resemble one with other

'Those hazel trees resemble one another.'

Second, -iş/-et in Romanian derive predicates that pattern with swarm nouns with respect to spatial stubbornly distributive predicates. They can only be predicated of the whole swarm, not the individuals that intuitively compose it. This shows that these derived nouns

\footnotetext{
${ }^{28}$ If one is worried about the restricted distribution of these suffixes, looking broader finds similar expressions with a wider distribution. For instance, the Mayan language Tzotzil has the suffix -tik that derives predicates of "expansive" individuals (Laughlin 1975). While -tik can affix tree species to derive nouns that intuitively denote swarms-e.g., tulan-tik 'oak grove' from tulan 'oak' - the same suffix also applies more generally to many nouns denoting inanimate objects-e.g., ton-tik 'rocky expanse' from ton 'rock' or ch'okiltik 'lumpy place' from ch'okil 'lump'. Even in Romanian, swarm-deriving suffixes are found that, which while not as productive, apply more widely. For instance, there is a third suffix -lic borrowed from Turkish, deriving groups of both animate and inanimate individuals-e.g., musafir-lîc "crowd of different guests' from musafir 'guest'. Chelaru-Ionita \& Bantas 1978 notes that many collectives derived by -lîc are derogatory. This might be explained by the fact that swarm nouns refer to individuals in virtue of their spatial extent, not their more human qualities, unlike teams or families. This same consideration most likely also explains why swarm derivations are commonly restricted to inanimate objects.
} 
denote individuals that are available for spatial predication based on the configuration of their constituent individuals, just like swarm nouns in English.

a. Alun-iş-ul acela este circular. hazel-group-DEF that is circular

'That hazel grove is circular.' SPEAKER COMMENT: This cannot mean that the trees themselves are circular.

b. Aluni-i aceia sint circulari. hazel-PL those are circular

'Those hazels are circular.' SPEAKER COMMENT: This can only mean that the trees themselves are circular.

Finally, nouns derived -iş/-et in Romanian share the high cardinality and spatial entailments we have already become familiar with for swarm nouns in English. In particular, nouns derived by -iş/-et denote collective individuals that must have a contextually specified large number of constituent individuals, not merely a simple plurality. In addition, these collective individuals they denote exist in virtue of the spatial configuration of those constituent individuals. For instance, moving apart the trees that constitute an alunis in (87a) will cause that grove to no longer exist.

These considerations show that nouns derived by -iş/-et in Romanian have the properties of swarm nouns in English. Given that the underived nominal stem in these examples does not necessarily have swarm reference, the straightforward analysis is that -iş/-et are semantically contentful, taking a nominal count predicate and returning a predicate of swarms composed of individuals in the extension of the stem. ${ }^{29}$ This analysis is illustrated in (88) for -iş, which when applied to aluni 'hazel', derives the swarm predicate in (89).

$$
\begin{aligned}
& \text {-iş } \rightsquigarrow \lambda Q \lambda x \exists \mathrm{P}\left[\operatorname{atom}(x) \wedge \varsigma(x)=\varsigma(f(x)) \wedge \operatorname{partition}(\mathrm{P}, \varsigma(x)) \wedge \text { fine }_{\mu=\text { area }}(\mathrm{P}) \wedge\right. \\
& \text { cluster } \left.\infty_{\infty}^{4}{ }^{p r o x}(\mathrm{P}) \wedge \forall s \in \mathrm{P} \exists y[\varsigma(y)=s \wedge Q(y)]\right]
\end{aligned}
$$

$$
\begin{aligned}
& \lambda x \exists \mathrm{P}\left[\operatorname{atom}(x) \wedge \varsigma(x)=\varsigma(f(x)) \wedge \operatorname{partition}(\mathrm{P}, \varsigma(x)) \wedge \text { fine }_{\mu=a r e a}(\mathrm{P}) \wedge \operatorname{cluster}_{\infty}^{4}{ }_{\text {prox }}(\mathrm{P})\right. \\
& \wedge \forall s \in \mathrm{P} \exists y[\varsigma(y)=s \wedge \operatorname{HAZEL}(y)]]
\end{aligned}
$$

s Under this analysis, $-i s ̧$ is completely parallel to the pluractional derivation in (70), except that it operates in the nominal domain. The broader conclusion is that swarm nouns are similar to event-internal pluractional verbs crosslinguistically, not just in their referential properties, but throughout their compositional morphosemantics. We find languages that have derived nouns with swarm reference, underived nouns with swarm reference, and derived verbs with swarm reference. This raises the question of whether the final cell in this typology is filled, namely whether there are verbs which lexicalize swarm reference in the event domain. These would be monomorphemic verbs with the semantics of

\footnotetext{
${ }^{29}$ We must, of course, ensure that these suffixes only compose with a restricted class of nouns denoting trees. This lexical restriction should be implemented in the lexicon using subcategorization frames, or a similar morphological mechanism like Vocabulary Insertion rules in DM (Halle \& Marantz 1993).
} 
an event-internal pluractional. While investigating this issue in depth must be left for future work, there are reasons to believe that there are many such verbs. In particular, many event-internal pluractional verbs crosslinguistically are best translated into English with monomorphemic verbs, not with the support of adverbials like repeatedly or frequently.

(90) SYRIAN ARABIC (Cowell 1964: p. 253)

safa? 'to slap/clap' $\rightarrow$ saffa? 'to applaud'

(91) Central Alaskan Yup'IK (Jacobson 1984: p. 497)

nere- 'to eat' $\rightarrow$ Neremciurtuq 'He nibbled.' (lit. eat a little at a time)

(92) KAQCHIKEL

chup- 'to turn off' $\rightarrow$ Xuchupüt" 'It flickered.'

There is a case to be made that verbs like those in (90-92), which are derived by pluractional markers in other languages, denote swarm events in English. ${ }^{30}$ Consider applaud, for instance. An applauding event is clearly composed of a plurality of clappings that fill a circumscribed interval of time, just as an event-internal pluractional would require. Moreover, these individual clappings are inaccessible to distributivity operators. For instance, example (93) has no reading where each student claps once in rapid succession, forming an applause. The pluractional subevents are just not accessible.

(93) The students applauded one by one.

(94) The students gathered in the park one by one.

Note that the problem cannot be that one by one requires each event in a satisfying sequence to fall in the extension of the verbal predicate. It is perfectly acceptable to say things like (94). The answer has to be that applaud does not make accessible those clapping events that intuitively make up an applause. In this way, it behaves like an eventinternal pluractional verb, though one that is clearly monomorphemic.

\section{Conclusions}

The existence of group nouns motivates two interrelated questions: How does natural language individuate collective entities, and how general is this process? This paper has answered the first question by showing that there is not just one way to do so. There are those that are defined in terms of the spatial and temporal configuration of their members,

\footnotetext{
${ }^{30}$ It is worth noting here that the noun swarm itself can be used as verb in English. In fact, it undergoes what has been called the "swarm-alternation", where the location of the event can be promoted to subject (Dowty 2000, 2001; Hoeksema 2009; Salkoff 1983). That said, not all swarm nouns correspond to verbs undergoing the swarm-alternation and not all verbs undergoing the swarm-alternation correspond to nouns with the semantic properties identified here-e.g., buzz. For this reason, I will leave an investigation of the eventive meaning of verbs like swarm for future work.
} 
called swarms, and there are those that are defined in terms of non-spatiotemporal notions. I then argued that these processes of collective individuation were generalizable across semantic domains. Not only do we find nouns denoting swarm individuals, but we find verbs denoting swarm events. In particular, I have shown that the crosslinguistically stable properties of event-internal pluractional verbs follow if they have swarm reference.

To make these arguments, especially the latter one, this paper has focused on pluractionality in the Mayan language Kaqchikel. First, it establishes for the first time that $-\mathrm{Ca}$, in Kaqchikel is an event-internal pluractional derivation. It then argues that $-\mathrm{Ca}$ ' derives predicates of swarm events. Crucially, all of the characteristics of event-internal pluractionality follow from this particular type of collectivity, which provides an improvement over previous approaches to the phenomenon. Finally, this paper showed that the kind of collective reference involved in event-internal pluractionality is mirrored in a split between types of collective nouns we find crosslinguistically, exemplified by the contrast between predicates like committee and grove. The latter are eventually called swarm nouns. Accounting for the contrasts between nouns and canonical group nouns means giving the former denotations that mirror event-internal pluractional verbs. Finally, I presented a few cross-categorial compositional similarities between swarm nouns and event-internal pluractionals that support a unified analysis.

A consequence of reducing event-internal pluractionality to a species of collective reference available in the nominal domain is that it supports a persistent intuition in the pluractional literature that pluractionality is the eventive counterpart of plurality in the individual domain. We know, though, from the extensive literature on nominal plurality that plural reference is not uniform. This immediately raises the question of which kinds of plural reference pluractional can verbs have. If the treatment of pluractionality in this work is on the right track, the answer is manifold. The fact that swarms can be used to account for the properties of certain nouns, as well as pluractional verbs, argues that the varieties of plural event reference are just as rich as plural reference in the nominal domain. Moreover, we can use the analysis of expressions in one domain to inform the analysis of expressions in the other, just like the analysis of Romanian -iş in (88) is supported by its close connection to pluractional derivations like $-\mathrm{Ca}^{\prime}$ in (70). The fact that we can use pluractionality to substantiate new classifications of nominals demonstrates the methodological richness of this approach.

Moreover, connecting event-internal pluractional verbs with swarm nouns reveals a telling asymmetry. The former have been discussed extensively, even though the data have mostly come from understudied languages, while swarm nouns in English, an extensively studied language, are new to the literature. This might be an accident, but it could also be because swarm nouns are less prevalent than their verbal counterparts, or less often morphologically distinguished, as they are in Romanian. These observations raise the larger theoretical question of whether languages employ similar representations with the same frequency across categories. It might be that swarm-denoting expressions are more pervasive in the verbal domain because events, in contrast to individuals, are naturally individuated by means of their spatial and temporal traces. While this paper does not address these kinds of ontological issues, a careful typological study of the frequency and productivity of morphemes that derive swarm nouns, as compared to their pluractional counterparts, should provide insight into this larger question. The ultimate goal is to 
know, not just where we find the same kinds of representations across nouns and verbs, but whether each kind is equally marked or unmarked across categories.

Finally, while this analysis has focused on finding parallels between pluractional verbs and types of group reference, it supports the wider program of finding cross-domain semantic parallels between verbs and nouns. This work has demonstrated that some types of pluractionality have aspectual effects, as seen in $\S 3$, and these effects can be treated as a consequence of the relevant pluractionals having a variety of group reference. It makes sense that other types of aspectual phenomena might also have their explanation in terms of noun-verb denotational parallels. This work then clearly fits into and is an extension of that large previous literature connecting the semantics of verbal and nominal categories, like that on telicity and the mass-count distinction or distributive predication and plurality.

\section{References}

[1] Bach, Emmon. 1981. Time, tense, and aspect: An essay in English metaphysics. In Peter Cole ed., Radical Pragmatics, 63-81. New York: Academic Press.

[2] Bach, Emmon. 1986. The algebra of events. Linguistics and Philosophy 9(1). 5-16. DOI: $10.1002 / 9780470758335$. ch13.

[3] Bar-El, Leora. 2008. Verbal number and aspect in Skwxwú7mesh. Recherches Linguistiques de Vincennes 37. 31-54. DOI: 10.4000 /rlv.1695.

[4] Barker, Chris. 1992. Group terms in English: Representing groups as atoms. Journal of Semantics 9(1).69-93. DOI: 10.1093/jos/9.1.69.

[5] Brasoveanu, Adrian \& Robert Henderson. 2009. Varieties of Distributivity: One by one vs. each. In Neil Ashton, Anca Chereches \& David Lutz eds., Proceedings of SALT 19, Ithaca, NY: CLC Publications. DOI: $10.3765 /$ salt . v19i0.2538.

[6] Carnoy, Albert J. 1917. Adjectival Nouns in Vulgar Latin and Early Romance. In Henry Alfred Todd \& Raymond Weeks eds., Romantic Review 8, 166-197. Lancaster, PA: Columbia University Press.

[7] Casati, Roberto \& Achille C. Varzi. 1999. Parts and places: The structures of spatial representation. MIT Press.

[8] Chacach, Martín, Marcos Cali \& Narciso Cojtí. 1999. Diccionario kaqchikel. Guatemala: Cholsamaj.

[9] Champollion, Lucas. 2010. Parts of a whole: Distributivity as a bridge between aspect and measurement. $\mathrm{PhD}$ thesis. University of Pennsylvania.

[10] Chelaru-Ionita, Oana \& Andrei Bantas. 1978. English vs Romanian collectives. Tech. rep. University of Bucharest. 
[11] Collins, Chris. 2001. Aspects of Plurality in $\neq$ Hoan. Language 77(3). 456-476. DOI: $10.1353 /$ lan.2001.0141.

[12] Cowell, Mark W. 1964. A reference grammar of Syrian Arabic. Cambridge: Cambridge University Press.

[13] Cusic, David. 1981. Verbal plurality and aspect. $\mathrm{PhD}$ thesis. Stanford University.

[14] Davies, Mark. 2008. COCA. Corpus of contemporary American English.

[15] De Swart, Henriëtte. 1998. Aspect Shift and Coercion. English. Natural Language \& Linguistic Theory 16(2).347-385. DOI: 10 .1023/A: 1005916004600.

[16] Dowty, David. 1979. Word meaning and Montague Grammar. Dordrecht: D. Reidel.

[17] Dowty, David. 2000. 'The garden swarms with bees' and the fallacy of 'argument alternation'. In Y. Ravin \& C. Leacock eds., Polysemy. Theoretical and Computational Approaches, 111-128. Oxford: Oxford University Press.

[18] Dowty, David. 2001. The semantic asymmetry of 'argument alternations' (and why it matters). Groninger Arbeiten zur Germanistischen Linguistik 44. 171186.

[19] Dressler, Wolfgang. 1968. Studien zur verbalen pluralität. Wien: Bülau in Kommission.

[20] Garrett, Andrew. 2001. Reduplication and infixation in Yurok: Morphology, semantics, and diachrony. International Journal of American Linguistics 67(3). 264-312. DOI: $10.1086 / 466460$.

[21] Grimm, Scott. 2012. Number and Individuation. $\mathrm{PhD}$ thesis. Stanford University.

[22] Gupta, Anil. 1980. The logic of common nouns. New Haven: Yale University Press.

[23] Halle, Morris \& Alec Marantz. 1993. Distributed Morphology and the Pieces of Inflection. In Kenneth Hale \& Samuel Jay Keyser eds., The View from Building 20, 111-176. Cambridge, Massachusetts: MIT Press.

[24] Henderson, Robert. 2012. Ways of pluralizing events. PhD thesis. University of California, Santa Cruz.

[25] Hinrichs, Erhard. 1985. A compositional semantics for Aktionsarten and NP reference in English. $\mathrm{PhD}$ thesis. Ohio State University. 
[26] Hoeksema, Jack. 2009. The swarm alternation revisited. In, Theory and Evidence in Semantics. Ed. by Hinrichs, Erhard \& John Nerbonne, 52-80. Stanford: CSLI Publications.

[27] Jacobson, Steven A. 1984. Yup'ik Eskimo dictionary. Fairbanks: Alaska Native Language Center, University of Alaska.

[28] Jespersen, Otto. 1924/1992. The philosophy of grammar. Chicago: University of Chicago Press.

[29] Kamp, Hans. 1979. Some remarks on the logic of change: Part I. In Christian Rohrer ed., Time, Tense and Quantifiers, Tübingen: Niemeyer.

[30] Krifka, Manfred. 1989. Nominal reference, temporal constitution and quantification in event semantics. In Renate Bartsch, Theo Vennemann \& Johan van Benthem eds., Semantics and Contextual Expression, 75-115. Dordrecht: Foris Publications.

[31] Krifka, Manfred. 1990. Four thousand ships passed through the lock: Objectinduced measure functions on events. Linguistics and Philosophy 13(5). 487520. DOI: $10.1007 / \mathrm{BF} 00627291$.

[32] Krifka, Manfred. 1992. Thematic relations as links between nominal reference and temporal constitution. In Ivan Sag \& Anna Szabolcsi eds., Lexical matters, 29-54. Stanford: CSLI Publications.

[33] Krifka, Manfred. 1998. The origins of telicity. In Susan Rothstein ed., Events and Grammar, 197-235. Dordrecht: Kluwer Academic Publishers.

[34] Landman, Fred. 1989a. Groups, I. Linguistics and Philosophy 12(5). 559-605. DOI: $10.1007 / \mathrm{BE} 00627774$.

[35] Landman, Fred. 1989b. Groups, II. Linguistics and Philosophy 12(6). 723-744. DOI: $10.1007 / \mathrm{BF} 00632603$.

[36] Landman, Fred. 1991. Structures for Semantics. Dordrecht: Kluwer Academic Publishers.

[37] Landman, Fred. 2000. Events and plurality: The Jerusalem lectures. Dordrecht: Kluwer Academic Publishers.

[38] Lasersohn, Peter. 1995. Plurality, conjunction and events. Dordrecht: Kluwer Academic Publishers.

[39] Lasersohn, Peter. 1998. Generalized distributivity operators. Linguistics and Philosophy 21(1). 83-93. DOI: 10.1023/A:1005317815339. 
[40] Laughlin, Robert M. 1975. The great Tzotzil dictionary of San Lorenzo Zinacantan. Washington, DC: Smithsonian Institution.

[41] Link, Godehard. 1983/2002. The logical analysis of plurals and mass terms: A lattice-theoretical approach. In Paul Portner \& Barbara Partee eds., Formal Semantics: The Essential Readings, 127-146. Oxford: Blackwell.

[42] Link, Godehard. 1998. Algebraic Semantics in Language and Philosophy. Stanford: CSLI Publications.

[43] Mourelatos, Alexander P. D. 1978. Events, processes, and states. Linguistics and Philosophy 2(3).415-434. DOI: $10.1007 / \mathrm{BF} 00149015$.

[44] Parrish, Julia K, Steven V Viscido \& Daniel Grünbaum. 2002. Self-organized fish schools: An examination of emergent properties. The Biological Bulletin 202(3). 296-305. DOI: $10.2307 / 1543482$.

[45] Pearson, Hazel. 2011. A new semantics for group nouns. In Mary Byram Washburn ed., Proceedings of WCCFL 28, 160-168. Somerville, MA: Cascadilla Proceedings Project.

[46] Persson, Gunnar. 1989. On the semantics of collective nouns in English. In Gunnar Persson Bengt Odenstedt \& Mats Rydén eds., Instead of flowers: Papers in honour of Mats Rydén on the occasion of his sixtieth birthday, 179-195. Stockholm: Almqvist \& Wiksell.

[47] Richards, Michael. 2003. Atlas lingüístico de Guatemala. Guatemala: Editorial Serviprensa.

[48] Ritchie, Katherine. 2013. What are groups? Philosophical Studies 166(2). 257272. DOI: $10.1007 /$ s11098-012-0030-5.

[49] Rothstein, Susan. 2004. Structuring Events: A Study in the Semantics of Lexical Aspect. Oxford: Blackwell.

[50] Rothstein, Susan. 2010. Counting and the Mass/Count Distinction. Journal of Semantics 27(3). 343-397. DOI: $10.1093 /$ jos / ffq007.

[51] Salkoff, Morris. 1983. Bees are swarming in the garden: A systematic synchronic study of productivity. Language 59(2). 288-346. DOI: 10 . 2307 / 413576.

[52] Schwarzschild, Roger. 2011. "Stubborn distributivity, multiparticipant nouns and the count/mass distinction". InProceedings of NELS 39. Ed. by Suzi Lima, Kevin Mullin \& Brian Smith. 1-18. 
[53] Smith, Barry. 1996. Mereotopology: A theory of parts and boundaries. Data \& Knowledge Engineering 20(3). 287-303. DOI: $10.1016 /$ S0169-023X (96) $00015-8$.

[54] Taylor, Barry. 1977. Tense and continuity. Linguistics and Philosophy 1(2). 199-220. DOI: 10.1007 /BF 00351103.

[55] Verkuyl, Henk J. 1972. On the compositional nature of the aspects. Dordrecht: D. Reidel. DOI: $10.1007 / 978-94-017-2478-4$.

[56] Wood, Esther Jane. 2007. The semantic typology of pluractionality. PhD thesis. University of California, Berkeley.

[57] Xrakovskij, Viktor S. 1997. Typology of Imperative Constructions. München: Lincom Europa. 